Review Article

\title{
MicroRNA Regulation of Brain Tumour Initiating Cells in Central Nervous System Tumours
}

\author{
Neha Garg, ${ }^{1,2}$ Thusyanth Vijayakumar, ${ }^{1,3}$ David Bakhshinyan, \\ Chitra Venugopal, ${ }^{1,2}$ and Sheila K. Singh ${ }^{1,2,3,4}$ \\ ${ }^{1}$ McMaster Stem Cell and Cancer Research Institute, McMaster University, Hamilton, ON, Canada L8S 4K1 \\ ${ }^{2}$ Department of Surgery, Faculty of Health Sciences, McMaster University, 1200 Main Street West, Hamilton, ON, Canada L8N $3 Z 5$ \\ ${ }^{3}$ Department of Biochemistry and Biomedical Sciences, Faculty of Health Sciences, McMaster University, 1200 Main Street West, \\ Hamilton, ON, Canada L8N $3 Z 5$ \\ ${ }^{4}$ Michael G. DeGroote School of Medicine, McMaster University, 1200 Main Street West, Hamilton, ON, Canada L8N $3 Z 5$
}

Correspondence should be addressed to Neha Garg; nehagarg.1986@gmail.com

Received 23 January 2015; Revised 19 March 2015; Accepted 10 April 2015

Academic Editor: Benedetta Bussolati

Copyright (C) 2015 Neha Garg et al. This is an open access article distributed under the Creative Commons Attribution License, which permits unrestricted use, distribution, and reproduction in any medium, provided the original work is properly cited.

CNS tumours occur in both pediatric and adult patients and many of these tumours are associated with poor clinical outcome. Due to a paradigm shift in thinking for the last several years, these tumours are now considered to originate from a small population of stem-like cells within the bulk tumour tissue. These cells, termed as brain tumour initiating cells (BTICs), are perceived to be regulated by microRNAs at the posttranscriptional/translational levels. Proliferation, stemness, differentiation, invasion, angiogenesis, metastasis, apoptosis, and cell cycle constitute some of the significant processes modulated by microRNAs in cancer initiation and progression. Characterization and functional studies on oncogenic or tumour suppressive microRNAs are made possible because of developments in sequencing and microarray techniques. In the current review, we bring recent knowledge of the role of microRNAs in BTIC formation and therapy. Special attention is paid to two highly aggressive and well-characterized brain tumours: gliomas and medulloblastoma. As microRNA seems to be altered in the pathogenesis of many human diseases, "microRNA therapy" may now have potential to improve outcomes for brain tumour patients. In this rapidly evolving field, further understanding of miRNA biology and its contribution towards cancer can be mined for new therapeutic tools.

\section{Introduction}

MicroRNAs are small (19-25 nucleotides) noncoding RNAs that bind within the $3^{\prime}$ untranslated region (UTR) of protein coding mRNAs [1] and regulate gene expression. This sequence-dependent posttranscriptional regulation of gene expression occurs either by repressing translation or degradation of target mRNAs [2]. Recently, a novel regulatory mechanism to regulate transcription or stimulate translation by binding to gene promoters or $3^{\prime}$ - and $5^{\prime}$-UTRs of mRNAs, respectively, is attributed to miRNAs $[3,4]$. As far as their biogenesis is concerned, when miRNA sequences are transcribed, they are formulated into hairpin-like structures called pri-microRNAs [5]. The primary transcripts are initially cleaved by a RNase III enzyme known as Drosha in the nucleus, which leads to the production of precursor miRNAs
(pre-miRNAs) [5]. Once the pre-miRNAs are transported into the cytoplasm, a second set of RNase III Dicer enzymes cleave the transcript to produce mature miRNAs [6]. miRNAs are associated with RNA-induced silencing complex (RISC) before they can acquire the full ability to bind their target mRNA [7]. Each miRNA can target multiple transcripts and together all the miRNAs are postulated to regulate about onethird of the human genome [8].

\section{Deregulation of MicroRNAs in Cancer}

Many human diseases, including cancer, have aberrant miRNA expression compared to normal healthy individuals [9]. In recent years, researchers have uncovered modifications at the level of genome processing. Genetic and epigenetic 
changes in the genome or amplification or deletion of regions can contribute to deregulation of microRNA levels [10, 11]. It has been predicted that about $45 \%$ of all pre-miRNAs have a minimum of one transcription factor binding site motif. The transcription factors can bind at conventional binding sites on the promoter of pre-miRNAs or have the ability to regulate microRNA processing by binding directly to the pri-miR and/or pre-miR [12]. An example is shown by the presence of Smad binding elements in pre-miRNAs responsive to TGF- $\beta /$ BMP-4 stimulation [13]. Other examples for miRNA regulators include p53 [14], E2F [15], and Myc [16], the most common transcription factors for cell cycle regulation and guarding the genome. CpG hypermethylation [17] and aberrant enzymes/components of microRNA processing like Dicer or Drosha [18] also have the potential to regulate miRNAs. miRNAs can modulate all the "hallmarks of cancer" described by Hanahan and Weinberg, that is, uncontrolled proliferation, resisting apoptosis, and stimulating new pathways that can help in cancer invasion and metastasis like angiogenesis [19]. Therefore, microRNAs, although small, are critical regulators of cancer initiation and progression, and in the subsequent sections we will discuss their role in brain tumour initiation in more detail.

\section{Cancer Stem Cell Hypothesis and Brain Tumour Initiating Cells}

Many solid tumours are composed of varied cell types including vascular tissues, inflammatory cells, neighboring fibroblasts, and neoplastic/cancerous cells [20]. The majority of cells may not drive tumour formation, whereas a minority of stem cells population within the tumour is exclusively capable of self-renewal and driving tumour growth. These cells are termed as cancer stem cells (CSCs) or tumour initiating cells (TICs) [21]. This elegant concept has reemerged only recently, although its origin can be traced to 1855 [22]. The first CSCs were described in acute myeloid leukemia (AML) [23]. To prevent the tumour from relapse after standard oncology treatments, many cancer therapies are now focused on eradication of CSCs. Therefore a complete molecular and physiological understanding of CSCs in their niche is needed to achieve this goal.

After the initial discovery of prospective breast cancer stem cells [24], brain tumour initiating cells (BTICs) [25] were characterized, raising the possibility of a hierarchical organization of solid tumours. Furthermore, these rare BTICs were able to reproduce a complete heterogeneous cancer that is of similar composition as the original cancer from which it was harvested [25]. BTICs that can be distinguished, based on their abnormal stem cell-like properties, can further be identified based on markers. CD133, also referred to as prominin-1 (PROM1), is a pentaspan transmembrane cell surface protein which has gained popularity as a CSC marker [25]. The initial work applying CD133 as a BTIC marker supported CSCs to be highly associated with CD133 expression [25]. The CD133+ subpopulation within a heterogeneous GBM culture has been proven to exhibit stem-like properties such as selfrenewal, high proliferation, and multipotency and at the same time this population has increased resistance to radiation treatments in comparison to CD133- GBM cells [26-29]. Although CD133 has been utilized as a BTIC marker, much is still unknown of this protein at the functional level. Further research in the past several years alluded to the discovery of additional markers such as CD15. CD15, also known as stage-specific embryonic antigen-1 (SSEA-1) or Lewis X, was initially assessed as a marker for neural stem cells (NSCs) and neural precursor cells (NPCs) in the brain [30]. In a mouse model of medulloblastoma, it was postulated that CD15+ cells were more effective at propagating tumours in comparison to CD133+ cells [31]. However, it is still conceded by multiple studies that the combination of evaluating both of these markers would provide a more accurate identification of BTICs [29, 31, 32]. The aforementioned CD133 and CD15 and even other novel proteins such as CD271 are categorized as external markers of BTICs and are used in various staining techniques to isolate them [33]. Recent research has also uncovered many cell-intrinsic markers that mark cells with tumorigenic properties. Many of these novel markers have been previously described as NSC markers. One of these, Bmil, is a member of the polycomb group proteins, which is notably involved in self-renewal of NSCs and CSCs through means of repressing the INK4a/ARF locus [34]. Other more regularly used internal markers of BTICs include Sox2, FoxG1, Oct4, Twist1, and Nestin [35-38]. Nanog, a transcription factor involved in maintaining self-renewal of embryonic [39] and adult neural stem cells [40, 41], has also been shown to provide stemness in BTICs [41, 42]. Aldehyde dehydrogenase $(\mathrm{ALDH})$ is an enzyme that plays a critical role in the metabolism and detoxification of external and internal substances. ALDH has also been found to be highly upregulated not only in NSCs but also in BTICs [43]. ALDH contributes to high proliferation rate and increased resistance to chemotherapy and radiation of BTICs [43]. Thus, ALDH is considered to be a BTIC marker. Other markers of BTICs include ABCG2, a key member within the $\mathrm{ABC}$ transporter family. This marker plays a potential role in multidrug resistance [44]. These transporters are highly expressed in CSCs and act to prevent the deterioration of these cells by means of blocking xenobiotic toxins [44].

\section{MicroRNAs in Brain Tumour Initiating Cells}

miRNAs play an important role in cellular development and growth. However, in the case of cancers, aberrant miRNA levels may play a functional role in pathogenesis. Despite evidence for the key roles that miRNAs play in brain tumour pathogenesis [45], clinically relevant knowledge of the prognostic, diagnostic, and therapeutic potential of these RNA particles in BTICs is yet to be elucidated. The implications of miRNAs in BTICs of CNS tumour for both pediatric and adult patients are discussed below.

\section{Gliomas}

Gliomas are divided according to their histological features into four grades by World Health Organization (2007) [46]. 
This classification from grade I to grade IV also stratifies gliomas from slow developing tumours to highly aggressive and infiltrative ones. The most aggressive grade IV glioma and accounting for almost half of the gliomas is Glioblastoma (GBM) [47]. GBM patients have a 5-year survival rate of less than $10 \%$ [48] despite advanced treatments with a combination of surgery, radiotherapy, and chemotherapy. As in the case of majority of brain tumours, selective cells within tumours are responsible for initiation and maintenance of gliomas and these are termed as glioma stem cells (GSCs) $[25,28]$. The first study that described GSCs used surgical specimens of patient GBMs and characterized stem cell populations through neurosphere and clonogenic assays [49]. From then, there has been robust knowledge development in comparing normal stem cells and BTICs responsible for gliomas. These similarities are based on shared characteristics such as self-renewal, proliferation, differentiation, and expression of cell surface and internal markers including CD133, CD15, Bmil, Nestin, Nanog, and Oct4 [29, 42, 50, 51]. Although there is some controversy with respect to the functional significance and labelling of GSCs, methods such as side population analysis [52], marker characterization, and use of in vitro culture [28] are useful tools for the enrichment and analysis of GSCs. Further studies of regulatory mechanisms underpinning GSCs are therefore warranted, and, more recently, there has been an increased focus on the functional role of microRNA (miRNA) in GSCs [53].

Ciafrè et al. and Chan et al. performed the first studies on miRNA expression profiles in GBM in 2005. Ciafrè et al. [54] demonstrated aberrant expression profiles of numerous miRNAs such as miR-221 which were strongly upregulated in GBM and miRNAs such as miR-128, miR-181a, miR-181b, and miR-181c which were shown to be downregulated in GBM. Chan et al. [55] also investigated the functional properties of miR-21 as an oncogenic microRNA. Since then, largescale studies on GBM and GSCs were performed to elucidate miRNA-mediated mechanisms of tumorigenesis.

\section{6. miRNAs as Tumour Suppressors in GBM}

In human U251 GSCs, miR-125b was amongst the first few microRNAs found to be downregulated and shown to play a role in GSC maintenance [56, 57]. miR-125b overexpression was found to decrease the expression of cell cycle regulatory proteins, CDK6 and CDC25A, thereby preventing cell cycle arrest at the G1/S transition [56]. Another group reported the downregulation of miR-125b in CD133+ GSCs [58]. This downregulation of miR-125b leads to E2F2 expression and cell cycle progression [58]. An alternate mechanism described the effects of miR-125b on the invasion of CD133+ GSCs cells. The changes in expression of matrix metalloproteinases (MMP-2 and MMP-9) and their corresponding inhibitors (RECK and TIMP3) by miR-125b aid GSCs to infiltrate the brain [56].

Oncogenic receptor tyrosine kinases epithelial growth factor receptor (EGFR) and platelet-derived growth factor receptor-a (PDGFR) are targeted by miR-128 [59, 60]. Recent studies showed that miR-128 also modulates other mitogenic kinases such as oncogenic receptor tyrosine kinases (RTKs) in gliomas [60]. Overexpression of miR-128 is accompanied by a decrease in histone methylation $\mathrm{H} 3 \mathrm{~K} 27 \mathrm{me}(3)$ and Akt phosphorylation [59]. In addition, Bmil, a stem cell marker and an oncogene, is directly targeted by miR-128 [59]. Overexpression of miR-128 was shown to downregulate the activity of p70S6 K1 and expression of its downstream signaling molecules such as HIF-1 and VEGF and reduced cell proliferation, tumour growth, and angiogenesis [61]. p70S6K1, a key downstream target of mammalian rapamycin (mTOR), is a direct target of miR-128 which plays a role in glioma tumour angiogenesis [61]. Transcription factor E2F3 was also reported as a target of miR-128 in glioma cells [62].

Many other miRNAs also function primarily as tumour suppressors. Overexpression of miR-143 inhibited glycolysis, promoted differentiation, and decreased tumorigenic capacity of GSCs in vivo, underscoring its important role as a tumour suppressor [63]. The expression of miR-153 that functions as an oncosuppressor was found to be downregulated in GBM tissues and in cultured CD133+ GSCs. Transfection of miR-153 into these GSCs induced differentiation and apoptosis and stalled tumour growth [64]. miR-7 was implicated in GBM as a tumor suppressor by regulating epidermal growth factor receptor (EGFR) and the Akt pathway. Moreover, miR-7 transfection was shown to decrease viability and invasiveness of GBM cells [65]. Recently, miR-145 was shown to inhibit migration and invasion of GSCs by targeting ATPbinding cassette transporter protein (ABCG2) [66]. This microRNA is normally expressed in neurons but has reduced expression in GBMs [66].

The universal anticancer gene, p53, is also linked to microRNAs in GSCs. miR-34a expression was downregulated in mutant p53 gliomas as compared with wild-type p53 gliomas [67]. miR-34a transfection inhibited survival, proliferation, cell cycle progression, cell invasion, and in vivo glioma xenograft growth and induces differentiation in GSCs $[67,68]$. In addition, a recent report suggested that miRNA34a regulates Akt and Wnt signaling pathways to suppress the proliferation and tumor growth of GSCs [69]. Oncogenes such as c-Met, Notch-1, and Notch-2 are the direct targets of miR-34a in GSCs [68]. Other members of miR-34 family, that is, miR-34c-3p and miR-34c-5p, also affect proliferation and invasion of glioma cells but with a differential activity [70].

Many microRNAs function effectively in modulating cell signaling. Downregulation of Notch-1 by miR-146a in GBM decreases migration of GSCs, thereby classifying miR-146a as an oncosuppressor [71]. miR-107 was reported to Notch2 by Chen et al. in 2013 [72]. miR-326 was shown to reduce growth, invasion, and tumorigenicity of GBM stem cells by targeting Notch-1, Notch-2, and pyruvate kinase muscle enzyme (PKM2) [73]. miR-107 suppressed proliferation, downregulated stem cell markers (CD133 and Nestin), reduced MMP-12 expression, and concealed GSCs xenograft growth in vivo [72]. In glioma cells, miR-622 inhibited tumor invasion and migration by targeting activating transcription factor 2 (ATF2) [74]. In vivo as well as in vitro data explored the role of miR-152 as a tumor suppressor in GBM stem cells [75]. Krüppel-like factor 4 (KLF4) was suggested as the downstream target of miR-152. The downregulation of KLF4 by overexpressing miR-152 leads to attenuation of the activation of MEK1/2 and PI3K signal pathways [75]. miR-218 
is one of the commonly downregulated microRNAs in GSCs [76] which targets Bmil. This again emphasizes the fact that microRNAs regulate key molecules in GSCs [76].

miR-124 and miR-137 are two oncosuppressors whose overexpression can induce differentiation and G1 cell cycle arrest of GSCs [77]. Both microRNAs bind to CDK6, a G1/S cell cycle regulator, and thereby induce differentiation of GSCs [17, 77]. Overexpression of miR-124 resulted in targeting of Neural Crest Transcription Factor Slug (SNAI2), which in turn inhibits tumorigenicity of gliomas and invasion in vivo [78]. Glioma pathogenesis-related protein 1(GLIPR1) or RTVP-1 is a direct target of miR-137 and this is another mechanism by which miR-137 inhibits stemness in GSCs [79]. A recent report shows the broader impact of miR-137 by regulating multiple genes in GBM. Using high throughput RNA sequencing (RNAseq) and RNA-binding protein immunoprecipitation sequencing (RIPseq), the authors have predicted miR-137 targets such as c-KIT, YBX1, Akt2, CDC42, CDK6, and TGF $\beta 2$ [80]. miR-451 is reported to suppress tumour growth both in gliomas [81] and GBM stem cells [82].

Last but not least, members of the microRNA miR-200 family are key regulators of cell proliferation, cell cycle, and tumour growth in gliomas and GSCs. In gliomas, miR-200b suppresses tumour cell growth by targeting the CREB1 gene [83]. Low expression levels of miR-200b are linked with poor prognosis in glioma patients [84]. In gliomas, miR-200b also targets multiple members of RAB family [85]. Another member of miR-200 family, miR-200a, downregulates singleminded homolog 2-short form (SIM2-s) [86]. SIM2-s is elevated in many human cancers and in gliomas; it facilitates tumour growth and invasion [86].

\section{7. miRNAs as Oncogenes in GBM}

Alternative classes of microRNAs called oncomiRs or oncogenic microRNAs were found to be deregulated in GSCs. These include the miR-10 family [87] (miR-10a and miR-10b) and miR-17-92 cluster. Repressed expression of tumour suppressor genes CUB and SUSHI was observed upon upregulation of miR-10 family members [87]. As described by Guessous et al., miR-10b inhibition significantly diminishes in vivo tumour formation and also reduces proliferation and invasion of GSCs [88]. The first oncomiR cluster miR-17-92 [89] and miR-9 were found to be enriched in GSCs. The miR-9 target calmodulin-binding transcription activator 1 (CAMTA1) functions as a tumor suppressor [90]. The miR-17-92 cluster is associated with downregulation of CTGF and PTEN in GBM stem cells [91, 92]. OncomiR-138 has recently been identified as part of a molecular signature and prognostic biomarker of GSCs [93]. miR-330, miR-582-5p, and miR-363 promote GSC migration and invasion by reducing apoptosis [94, 95]. miR-1275 induces GSC proliferation via a polycomb mediated silencing mechanism and silencing of Claudinll protein [96].

\section{8. miRNAs in Pediatric Glioma}

Although infrequent in children (about 15\% of brain tumors), pediatric high grade gliomas (pHGG) account for high mortality [97] which depending on the key signaling pathways and copy number [98] is differentiated from adult high grade gliomas (aHGG). The deregulation of miR-129, miR142-5p, and miR-25 in pHGG has been reported using four samples [99]. However, the high throughput microRNA study comparing pHGG, aHGG, and normal brain tissues showed the upregulation of oncogenic miR-17-92 cluster and miR21 in pHGG [92]. Moreover, using pHGG cell lines, it was showed that the modulation of proliferation and tumorigenic signaling by miR-17-92 cluster in pHGG was by targeting tumour suppressors like PTEN and RB1.

All the above findings both in adult and pediatric gliomas suggested that microRNAs in gliomas and GSCs have a potential role in regulating fundamental core stem cell pathways and directing the fate of cancerous tissue to be either benign or malignant. A summary is provided in Table 1.

\section{Medulloblastoma}

Childhood cancers are the leading cause of disease-related mortality in children [100]. Medulloblastoma (MB) is the most common malignant brain tumour in children [100]. $\mathrm{MB}$ is often associated with disruption or deregulation of cerebellar development could occur in either pre- or postnatal developmental windows. MB is found to arise from cells in the external granular layer (EGL) or the subependymal matrix residing within the cerebellum [101]. MB has the potential to metastasize along the spinal cord, which portends a worse prognosis [102]. Current regimens for treatment of MB include a combination of surgery, craniospinal radiotherapy, and chemotherapy. Yet, depending on which of the 4 subgroups (Wnt, Shh, group 3, and group 4) the MB is classified into, the clinical outcome varies [102]. These four distinct groups are formulated according to the unique molecular characteristics previously described [101, 103, 104]. Despite the effectiveness of modern cancer therapies, long-term side effects are demonstrated in patients by cognition defects and developmental delays [105]. Furthermore, tumour recurrence occurs in 20 to $30 \%$ of all patients with clinical outcomes that are far worse than they were at primary diagnosis [106].

9.1. MicroRNAs as Tumor Suppressors in MB. miRNAs are highly associated with many cancers, and their role has also been described in MB [107]. Ferretti et al. in 2008 was one among the first to illustrate the characterization of miRNA in [108]. In their study, miR-125b, miR-324-5p, and miR326 were demonstrated as the suppressors of sonic hedgehog signaling (Shh) pathway and MB cells showed increased proliferation when these microRNAs were diminished. The same group in 2009 depicted several microRNAs to be involved in regulation of BTICs in MBs [109]. miR-9 and miR-125 were the most promising as growth-inhibitory and apoptotic microRNAs for BTICs [109]. Another group in 2008 uncovered the role of miR-124 in MB [110]. miR-124 shows decreased expression levels in MB cells [111], with its restoration leading to inhibition of cell proliferation [110]. miR-124 is normally expressed in external granule cells of the cerebellum, which may represent a cell of origin in MB [110]. Cyclin dependent kinase 6 (CDK6) [110] and solute carrier 
TABLE 1: miRNAs regulating BTICs in gliomas and GBM stem cells.

\begin{tabular}{|c|c|c|c|}
\hline MicroRNAs & Targets & Expression in GSCs & Reference \\
\hline \multicolumn{4}{|c|}{ Adult patients } \\
\hline miR-128 & RTKs, EGFR, PDGFR, Akt, Bmil, HIF-1, VEGF, E2F3 & Downregulated & {$[54,59-62]$} \\
\hline miR-181a, b, c & Bcl-2, & Downregulated & {$[54,184]$} \\
\hline $\operatorname{miR}-125 b$ & CDK6, CDC25A, E2F2, MMP-2, MMP-9, RECK, TIMP3 & Downregulated & {$[56-58]$} \\
\hline miR-143 & N-RAS, PI3K/Akt, MAPK/ERK & Downregulated & {$[57,63,185]$} \\
\hline miR-153 & Bcl-2, Mcl-1 & Downregulated & {$[64,186]$} \\
\hline miR-7 & EGFR, Akt & Downregulated & {$[65]$} \\
\hline miR-145 & ABCG2 & Downregulated & {$[66]$} \\
\hline miR-34a & Akt, Wnt pathway, c-Met, Notch-1, Notch-2 & Downregulated & {$[66,67,69]$} \\
\hline $\operatorname{miR}-34 c-3 p, 5 p$ & Notch-2 & Downregulated & [70] \\
\hline miR-146a & Notch-1 & Downregulated & {$[71]$} \\
\hline miR-326 & Notch-1, Notch-2, PKM2 & Downregulated & {$[73]$} \\
\hline miR-107 & Notch-2, MMP-12 & Downregulated & {$[72]$} \\
\hline miR-622 & ATF2 & Downregulated & [74] \\
\hline miR-152 & KLF4 & Downregulated & {$[75]$} \\
\hline miR-218 & Bmil & Downregulated & {$[76]$} \\
\hline miR-124 & SNAI2, CDK6 & Downregulated & {$[17,77,78]$} \\
\hline miR-137 & RTVP-1, c-KIT, YBX1, Akt2, CDC42, CDK6, TGF $\beta 2$ & Downregulated & {$[77,79,80]$} \\
\hline miR-451 & PI3K/Akt pathway & Downregulated & {$[81,82]$} \\
\hline miR-200 family & CREB1, RAB family, SIM2-s & Downregulated & {$[83-86]$} \\
\hline miR-221, miR-222 & p27 and p57 & Upregulated & {$[54,187]$} \\
\hline miR-21 & FASLG, FOXO1, IGFBP3, FBXO11 & Upregulated & {$[55,188-191]$} \\
\hline miR-10 family & CUB, SUSHI & Upregulated & {$[87,88]$} \\
\hline miR-17-92 cluster & CTGF, PTEN & Upregulated & {$[91,92]$} \\
\hline miR-9 & CAMTA1 & Upregulated & {$[90]$} \\
\hline miR-300 & SH3GL2 & Upregulated & {$[95]$} \\
\hline miR-582-5p & Caspase3, caspase9, Bim & Upregulated & {$[94]$} \\
\hline miR-363 & Caspase 3 , caspase9, Bim & Upregulated & {$[94]$} \\
\hline miR-1275 & Claudin11 & Upregulated & [96] \\
\hline \multicolumn{4}{|c|}{ Pediatric patients } \\
\hline miR-129 & Undefined & Downregulated & [99] \\
\hline miR-142-5p & Undefined & Upregulated & [99] \\
\hline miR-25 & P57 & Upregulated & {$[99,192]$} \\
\hline miR-17-92 & PTEN, RB1 & Upregulated & [92] \\
\hline
\end{tabular}

family 16 (SLC16A1) [111] are the two identified key targets of miR-124 in MB. This suggests that miRNAs may be actively involved in the initiation and maintenance of $\mathrm{MB}$ through regulation of cell proliferation and cell cycle.

Role of miR-218 was also investigated in a Shh-dependent MB cell line. Cells with lower miR-218 levels presented increased tumour-like properties using both in vitro and in vivo experimental approaches [112]. Cell migration and invasion declined as miR-218 expression levels increased, suggesting miR-218 functioned as a tumour suppressor. Likewise, miR-199b-5p also functions as a tumour suppressor since overexpression of this miRNA leads to reduced tumour growth in MB [113]. Other studies further support miR-199b to be responsible for regulating BTICs within MB [114] by regulating the Notch pathway [113]. The miR-34 family was found to suppress CD15+/CD133+ BTICs. Similar to GBM, this effect was achieved by targeting the Notch-signaling pathway [115]. miR-34a overexpression in an in vitro study displayed inhibition of cell proliferation and cell invasion while simultaneously enriching chemotherapy sensitivity [68, 116]. Another recent study proved the role of miR-34a deficiency in accelerating MB formation in vivo [117].

Other studies focusing on Wnt-dependent MB show decreased expression of miR-193 and miR-224 to enhance cell proliferation and decrease radiosensitivity [118]. A small population of BTICs regulated by these microRNAs not only confers cancer stem cell characteristics in cells but also provides a means of evading therapies $[25,118,119]$.

Some of the microRNAs postulated during normal embryonic and NSC development may also regulate CSCs. One such example is miR-1280. A study demonstrated the appearance of cancer stem cell-like properties in MB cells upon decreasing miR-1280 expression [120]. Downregulation of miR-1280 leads to increased Jagged-2 that causes metastatic 
TABLE 2: miRNAs regulating BTICs in MB.

\begin{tabular}{|c|c|c|c|}
\hline MicroRNAs & Targets & Expression in MB/BTICs of MB & Reference \\
\hline \multirow{2}{*}{ miR-124 } & CDK6 & \multirow[t]{2}{*}{ Reduced } & \multirow[t]{2}{*}[110,111]{} \\
\hline & SLC16A1 & & \\
\hline miR-125b & \multirow{3}{*}{ Shh signaling pathway } & Reduced & [108] \\
\hline miR-324 & & Reduced & [108] \\
\hline $\operatorname{miR}-326$ & & Reduced & [108] \\
\hline miR-193 & \multirow{2}{*}{ Wnt signaling pathway } & Reduced & [118] \\
\hline miR-224 & & Reduced & {$[118]$} \\
\hline $\operatorname{miR}-1280$ & JAG2 & Reduced & {$[120]$} \\
\hline miR-218 & CDK6, RICTOR, CTSB & Reduced & {$[112]$} \\
\hline miR-199b & HES1 & Reduced & {$[113]$} \\
\hline miR-34a & c-MET, Notch-1, Notch-2, CDK6, MAGE-A, DLL2 & Reduced & {$[68,116,117]$} \\
\hline miR-9 & \multirow[t]{2}{*}{ ( } & Reduced & [109] \\
\hline miR-125 & & Reduced & [109] \\
\hline $\mathrm{miR}-128 \mathrm{a} / \mathrm{b}$ & Bmil & Reduced & [109] \\
\hline miR-135a & Arhgef6 & Reduced & [121] \\
\hline miR-21 & PDCD4 & Increased & {$[124,127]$} \\
\hline miR-182/96/183 & Wnt signaling pathway & Increased & [124] \\
\hline miR-17/92 & PTEN, Shh pathway & Increased & {$[109,122,123]$} \\
\hline miR-142 & GATA1, TAL1/E47 & Increased & {$[125]$} \\
\hline miR-30b/30d & Undefined & Increased & {$[128]$} \\
\hline
\end{tabular}

dissemination and poor outcome in MB patients [120]. Recently, miR-135a is shown to inhibit specifically cancer stem cell driven MB by targeting Arhgef6 (rho guanine nucleotide exchange factor 6), a gene frequently upregulated in $\mathrm{MB}$ [121]. This emphasizes the importance of miRNA mediated targeting of BTICs.

9.2. OncomiRs in $M B$. The famous oncomiR cluster miR17/92 family members, namely, miR-17 and miR-92, were found to be involved in Shh-dependent MB [122] as both were able to increase the proliferation rates of $\mathrm{MB}$ cells when overexpressed $[122,123]$. This polycistronic protooncogene miR-17/92 cluster is amplified in about $6 \%$ of pediatric MB [122]. These miRNAs were shown to either induce or maintain cancer stem cells in MB. This provides evidence of aberrant hedgehog signaling contributing to the pathogenesis of $\mathrm{MB}$ both at the level of gene expression and the level of miRNA deregulation.

Recently miR-21, miR-96, miR-182, miR-183, and miR$142-3 p$ [109, 124-127] were found to promote tumorigenesis and migration in BTIC of MB. The aforementioned microRNAs function by regulating proliferation, stemness, or escape from therapy. Oncosuppressor miR-128a/b [109] and oncomiRs miR-17, miR-92 $[122,123]$ plays a regulatory role in poor clinical outcome group $3 \mathrm{MB}$. miR-30b and miR-30d expressions may also be amplified in $\mathrm{MB}$, thereby suggesting these miRNAs as putative oncogenic targets [128]. A list of microRNAs modulating BTICs in MB is compiled in Table 2. However, it is still unclear whether many of these microRNAs are capable of directly regulating only BTICs or the whole tumour cells in $\mathrm{MB}$ as majority of the miRNAs affect both populations.

\section{Craniopharyngioma}

Craniopharyngioma (CP) is a benign tumour of the sellar region that is commonly diagnosed in children. Due to its unpredictable growth pattern, it is often associated with severe adverse neurological effects and significant reduction in quality of life [129]. Initially it was proposed that CP can originate from either the ectopic remnants of Rathke's Pouch (RP) or embryonal epithelial cells $[130,131]$, but the recent development of mouse models reveals a small population of cells in CP that share the properties with stem cells [132]. $\mathrm{Wnt} / \beta$-catenin pathway overactivation has been shown in these stem cells along with the high levels of secreted mitogenic signals like Shh, BMP, and FGF family. This model has provided first insight into putative CP BTICs [132]. Further studies have revealed that a fraction of cells with increased $\beta$-catenin levels have lower expression of Ki67 with long telomeres, both of which are the features of stem cells [133]. However, it is still unclear whether RP progenitors are truly responsible for CP initiation; therefore, a comprehensive analysis of microRNA signatures of those cells might provide the opportunity to conclusively elucidate the CP BTICs.

In 2013, Campanini et al. performed comprehensive microRNA expression profiling in CP in order to understand the role of microRNAs in CP tumorigenesis [134] (Table 3). One of the interesting findings of the paper is that, in tumours harbouring CTNNB1 mutation, there was downregulation of miR-16 and miR-141. Furthermore, in silico analysis demonstrated that miR-23b, miR-24-2, miR-141, and miR-449 act as tumour suppressors by inhibiting translation of CTNNB1 mRNA, while miR-150 was proposed to be acting as an oncomiR by modulating adenomatous polyposis coli (APC) 
TABLE 3: miRNAs regulating BTICs in other CNS tumours.

\begin{tabular}{|c|c|c|c|c|}
\hline Tumour & miRNA & Target/putative target & Expression level & References \\
\hline \multirow{14}{*}{ Pituitary adenoma } & miRNA-16-1 & BCL1 & Downregulated & {$[134]$} \\
\hline & Let-7 & HMGA2 & Downregulated & {$[156]$} \\
\hline & miR-128 & Bmil & Downregulated & {$[168-170]$} \\
\hline & miR-143 & ERK5 & Downregulated & {$[169,193]$} \\
\hline & miR-126 & PTTG1 & Downregulated & [178] \\
\hline & $\operatorname{miR}-381$ & PTTG1 & Downregulated & {$[178]$} \\
\hline & $\begin{array}{l}\text { miR-132, miR-136, miR-127, miR-129, miR-203, miR-134, } \\
\text { miR-127, miR-141, miR-145 }\end{array}$ & N/A & Downregulated & {$[168,176,194]$} \\
\hline & miRNA-128a & Weel & Upregulated & {$[169]$} \\
\hline & miRNA-155 & Weel & Upregulated & [169] \\
\hline & miRNA-516-3p & Wee1 & Upregulated & {$[168,169]$} \\
\hline & miR-26b & PTEN & Upregulated & {$[168-170]$} \\
\hline & miR-26a & PKCd & Upregulated & [195] \\
\hline & $\operatorname{miR}-212$ & DEDD & Upregulated & {$[176,177]$} \\
\hline & $\begin{array}{l}\text { miR-150, miR-152, miR-191, miR-192 miR-23a, miR-23b, } \\
\text { miR-24-2, miR-137 }\end{array}$ & N/A & Upregulated & {$[168,176,194]$} \\
\hline \multirow[t]{2}{*}{ Craniopharyngioma } & $\begin{array}{l}\text { miR-141, miR-16, miR-449, miR-145, let-7a, miR-143, } \\
\text { miR-23b, miR-15a, miR-24-2 }\end{array}$ & N/A & Downregulated & {$[134]$} \\
\hline & $\operatorname{miR}-150$ & N/A & Upregulated & {$[134]$} \\
\hline \multirow{4}{*}{$\mathrm{AT} / \mathrm{RT}$} & let-7b & HMGA2 & Downregulated & {$[99,154]$} \\
\hline & let-7a3 & HMGA2 & Downregulated & {$[99,154]$} \\
\hline & miR-140, miR-139, miR-153, miR-376b & $\mathrm{N} / \mathrm{A}$ & Downregulated & {$[99,154]$} \\
\hline & miR-520b, miR-629, miR-221, miR-498, miR-373 & N/A & Upregulated & {$[99,154]$} \\
\hline \multirow[t]{2}{*}{ Pilocytic astrocytoma } & $\begin{array}{l}\text { miR-93, miR-135a, miR-129, miR-135b, miR-106b, } \\
\text { miR-181b-5p }\end{array}$ & N/A & Downregulated & {$[99,180]$} \\
\hline & miR-432, miR-29a, miR-138, miR-299-5p, miR-34a & N/A & Upregulated & [99] \\
\hline \multirow[b]{2}{*}{ Ependymoma } & $\begin{array}{l}\text { miR-485-5p, miR-383, miR-139, miR-323, miR-433, miR-137, } \\
\text { miR-138, miR-124a, miR-181d, miR-193b }\end{array}$ & N/A & Downregulated & {$[99,143]$} \\
\hline & $\begin{array}{l}\text { miR-34a, miR-135a, miR-17-5p, miR-10a, miR-19a, miR-19b, } \\
\text { miR-20a, miR-21, miR-32, miR-34c, miR-34b, miR-200b, } \\
\text { miR-200a, miR-483miR-106b, miR-130a, miR-135a, } \\
\text { miR-142-3, miR-193, miR-210, miR-301, miR-449b, miR-502, } \\
\text { miR-518b, miR-551b, miR-565, miR-591, miR-594, miR-601 }\end{array}$ & $\mathrm{N} / \mathrm{A}$ & Upregulated & {$[99]$} \\
\hline
\end{tabular}

[134]. Although there is no direct correlation between BTICs and microRNA profiling for CP in this study, it gives an outline of microRNAs that are postulated in maintenance and signaling of other types of cancer stem cells [135-137]. Further studies are required to reveal a specific miRNA expression signature that will be used to identify a more proliferative, stem-like, and likely more aggressive case of CP, thereby allowing for discovery of novel therapeutic targets to mark CP BTIC populations.

\section{Ependymoma}

Ependymoma is a common pediatric and adult CNS tumour that is thought to originate from cells lining ventricular spaces and radial glial cells of the brain [138-140]. Although chemotherapy and radiotherapy comprise the standard regimen for the treatment of these patients, the patient outcome and 5-year survival remain poor due to recurrence $[139,141]$. There is still no biological marker that can be correlated with disease progression and prognosis [142]. A study by Costa et al. has identified 28 miRNAs (Table 3 ) that are differentially expressed in ependymoma when compared to normal ependymal cells [143]. An interesting finding emerging from the study was the identification of underexpressed miR-203 as an independent factor correlating with time to relapse, which ultimately can be used in disease management and prediction of ependymoma progression and recurrence [143]. Studies in other human cancers revealed the association of miR-203 with solid as well as hematopoietic malignancies. In leukemia, miR-203 has been implicated in the regulation of the $B C R$ $A B L$ gene $[144,145]$. Moreover, in skin, miR-203 is associated with repression of "stemness" [146]. A multivariate analysis using paraffin-embedded (FFPE) ependymoma samples from patients has identified let-7d, miR-596, and miR-367 to be associated with increased overall survival [143]. These 
microRNAs are shown to regulate stem cells in other cancers like breast and brain [147, 148]. Furthermore, miR-34a was shown to be overexpressed in supratentorial ependymomas which are associated with better prognosis in comparison to infratentorial tumours [143]. A signature of 5 miRNAs (miR376a, miR-381, miR-411, miR-432, and miR-487) along with miR-203 that can be mapped to both chromosome 14q32.1 and $14 \mathrm{q} 32.33$ is shown in ependymoma and other tumours to be regulated by DNA methylation, proving the global dysregulation of this chromosome in carcinomas $[143,149,150]$. Furthermore, a recent work published the role of miR-376a in the regulation of human dental stem cells [151]. This further emphasized a common mode of deregulation of microRNAs in stem cells and multiple cancer types that may be affecting only a small cell population which originate these tumours.

\section{Atypical Teratoid/Rhabdoid Tumours}

Atypical teratoid/rhabdoid tumours (AT/RT) are highly aggressive tumours characterized by biallelic inactivation of the SMARCB1/INI-1/hSNF5/BAF47 tumour suppressor gene $[152,153]$. Whole exome sequencing of AT/RT tissues performed by Zhang et al. has identified a copy number decrease of the genomic locus containing let-7a3 and let$7 b$ microRNAs as well as overexpression of HMGA2 [154]. They further showed that HMGA2 overexpression in AT/RT samples was not associated with the loss of SMARCB1. Similar to other human cancers $[155,156]$, the let-7 family negatively regulates the HMGA2 oncogene in AT/RT as well [154]. Interestingly, both overexpression of let-7a3 and let$7 \mathrm{~b}$ and knockdown of HMGA2 resulted in decreased cell proliferation and colony formation in a rhabdoid tumour cell line [154], emphasizing the role of these microRNAs in cells selected under stem cell conditions. Although the regulation of HMGA2 by let-7 miRNAs is not unique to AT/RT and has been previously discussed in breast [157], lung [158], and ovarian [159] cancers, it provides a new therapeutic avenue in management of AT/RT tumours.

Both the aggressive nature and heterogeneity of AT/RT can suggest the existence of BTIC population responsible for tumour initiation and growth [160-162]. A fraction of cells expressing stem cell marker CD133 was shown to have an increased expression of several developmental genes including Oct 4, Sox2, Nestin, and Bmil [163-165]. Although several gene expression studies have been conducted in attempt to further characterize AT/RT BTICs, there is still a need for development of in vivo models that will help in functionally evaluating the putative BTICs and the microRNAs deregulated in them.

\section{Pituitary Adenoma and Pilocytic Astrocytoma}

Pituitary adenomas are benign tumours that account for 10$15 \%$ of all diagnosed brain malignancies [166]. The cell of origin for pituitary tumours can be one of the five differentiated cell types: growth hormone- (GH-) secreting, adrenocorticotrophic hormone- (ACTH-) secreting, prolactin- (PRL-) secreting, thyroid-stimulating hormone- (TSH-) secreting, or nonfunctioning pituitary cells (NFA) within the pituitary gland [167]. The majority of pituitary adenomas are indolent, some pituitary tumours are associated with fast growth and even metastasis to distant site such as lymph nodes and liver [166]. Although recent studies demonstrated deregulated expression of several miRNAs in the pituitary adenomas, their function and target genes remain largely unknown. A likely difference between slow growing and fast growing tumours is cell cycle regulation. Several miRNAs have been reported to regulate the cell cycle in the pituitary adenomas. As mentioned in BTICs of MB and GBM, miR-128 is also downregulated in pituitary adenomas [168]. Important cell cycle regulatory proteins such as PTEN and Bmil are regulated by $\mathrm{miR}-26 \mathrm{~b}$ and $\mathrm{miR}-128$, respectively [168]. miR$128 \mathrm{a}$ and $\mathrm{miR}-155$ were found to be overexpressed in $\mathrm{GH}$ and NFA which resulted in the downregulation of Weel, a known cell cycle inhibitor $[169,170]$. This dual nature of miR128 family with its different members playing both oncogenic and tumour suppressor activities can be explained based on the microRNAs processing from pri-miR to pre-miR to the export in cytoplasm [171]. Three major mechanisms suggest the differential action of miR-128 in different cell types. They are point mutation/single nucleotide polymorphism [172], loss of heterozygosity ( $\mathrm{LOH}$ ) or amplification in miR-128 host gene ARPP21 [173], and epigenetic alteration of miR128 gene by $\mathrm{CpG}$-island methylation in promoter regions [44]. Be it any mechanism, the aberrant expression of miR128 family members needs further study to clarify its role in tumorigenesis and cancer progression [174, 175].

In addition to deregulation of cell cycle, an important hallmark of cancer is the ability of cells to evade apoptosis. miR-212 is shown to be strongly upregulated in pituitary tumours [176] and a study suggested death effector domaincontaining protein (DEDD) as its potential target. This is a protein involved in apoptosis signaling [177]. Despite rare cases of metastasis of pituitary tumours, there are reports linking miRNA deregulation to tumour invasion and metastasis $[178,179]$. Pituitary tumour transforming gene (PTTG) protein 1 is associated with increased tumour invasiveness [178] and is targeted by miR-126 and miR-381. These two microRNAs are downregulated in GH-secreting pituitary adenomas [179]. Furthermore, the differential expression of miRNAs is not uniform among all types of pituitary malignancies. For example, overexpression of miR-23a, miR-23b, and miR-24-2 and downregulation of miR-26b are common to GH-secreting and PRL-secreting pituitaries but are not observed in nonfunctioning adenomas [176].

Similar to pituitary adenomas, miRNA deregulation in pilocytic astrocytoma was shown to correlate with increased proliferation, migration, and evasion of apoptosis [99]. A study by Zhi et al. in 2014 demonstrated the association of miR-181b-5p downregulation with poor prognosis [180]. Increased tumor initiating cell properties were attributed to upregulated expression of neurooncological ventral antigen 1 (NOVA 1) that is normally regulated by miR-181b-5p [180], further emphasizing the role of targeting BTICs for complete eradication of cancer. 


\section{MicroRNAs: Therapeutic Applications}

Treatment of cancer may eventually necessitate a multimodal approach of traditional chemotherapy/radiotherapy regimens and nontraditional RNA-based approaches. MicroRNA/RNAi based therapeutics have the potential to overcome the ineffectiveness of current treatments by either silencing the oncogenes or blocking genes that cause downregulation of oncosuppressors. This kind of novel treatment requires the discovery and complete elucidation of the functional biology of microRNAs and effective targeted delivery to their molecular targets in cancer initiating and maintaining cells. The next critical step is to gain an understanding of microRNA profiling for cancerous versus healthy cells and corresponding functional analyses. Delivery to the CNS poses another big challenge due to the difficulties in crossing the blood brain barrier and other extracellular matrix components [181]. Nevertheless, this caveat can be overcome using strategies such as nanoparticles and liposomes as encapsulated carriers [182]. Another method could be to directly target therapies in brain tumour cells using viral delivery approaches [181]. Convection-enhanced delivery can be used postsurgically to deliver RNA molecules to the tumour bed [183].

In conclusion, further developments for microRNAmediated therapy are needed to provide clinicians with another avenue in treating the patients with deadly brain tumours. This will involve challenges in ensuring the stability and delivery of RNA therapeutics in in vivo systems and further depending on extent of the disease miRNAs can be used in conjunction with other available therapies.

\section{Conflict of Interests}

The authors declare that there is no conflict of interests regarding the publication of this paper.

\section{References}

[1] D. P. Bartel and C.-Z. Chen, "Micromanagers of gene expression: the potentially widespread influence of metazoan microRNAs," Nature Reviews Genetics, vol. 5, no. 5, pp. 396-400, 2004.

[2] H. R. Chiang, L. W. Schoenfeld, J. G. Ruby et al., "Mammalian microRNAs: experimental evaluation of novel and previously annotated genes," Genes \& Development, vol. 24, no. 10, pp. 9921009, 2010.

[3] S. Vasudevan, Y. Tong, and J. A. Steitz, "Switching from repression to activation: microRNAs can up-regulate translation," Science, vol. 318, no. 5858, pp. 1931-1934, 2007.

[4] S. Lee and S. Vasudevan, "Post-transcriptional stimulation of gene expression by MicroRNAs," Advances in Experimental Medicine and Biology, vol. 768, pp. 97-126, 2013.

[5] E. Lund, S. Güttinger, A. Calado, J. E. Dahlberg, and U. Kutay, "Nuclear export of microRNA precursors," Science, vol. 303, no. 5654, pp. 95-98, 2004.

[6] P. M. van Wynsberghe, S.-P. Chan, F. J. Slack, and A. E. Pasquinelli, "Analysis of microRNA expression and function," Methods in Cell Biology, vol. 106, pp. 219-252, 2011.
[7] S. Diederichs and D. A. Haber, "Dual role for argonautes in microRNA processing and posttranscriptional regulation of microRNA expression," Cell, vol. 131, no. 6, pp. 1097-1108, 2007.

[8] B. P. Lewis, C. B. Burge, and D. P. Bartel, "Conserved seed pairing, often flanked by adenosines, indicates that thousands of human genes are microRNA targets," Cell, vol. 120, no. 1, pp. 15-20, 2005.

[9] A. Gaur, D. A. Jewell, Y. Liang et al., "Characterization of microRNA expression levels and their biological correlates in human cancer cell lines," Cancer Research, vol. 67, no. 6, pp. 2456-2468, 2007.

[10] B. M. Ryan, A. I. Robles, and C. C. Harris, "Genetic variation in microRNA networks: the implications for cancer research," Nature Reviews Cancer, vol. 10, no. 6, pp. 389-402, 2010.

[11] G. A. Calin, C. Sevignani, C. D. Dumitru et al., "Human microRNA genes are frequently located at fragile sites and genomic regions involved in cancers," Proceedings of the National Academy of Sciences of the United States of America, vol. 101, no. 9, pp. 2999-3004, 2004.

[12] J. Piriyapongsa, I. K. Jordan, A. B. Conley, T. Ronan, and N. R. Smalheiser, "Transcription factor binding sites are highly enriched within microRNA precursor sequences," Biology Direct, vol. 6, article 61, 2011.

[13] B. N. Davis, A. C. Hilyard, P. H. Nguyen, G. Lagna, and A. Hata, "Smad proteins bind a conserved RNA sequence to promote MicroRNA maturation by Drosha," Molecular Cell, vol. 39, no. 3, pp. 373-384, 2010.

[14] L. He, X. He, L. P. Lim et al., "A microRNA component of the p53 tumour suppressor network," Nature, vol. 447, no. 7148, pp. $1130-1134,2007$.

[15] Y. Sylvestre, V. de Guire, E. Querido et al., "An E2F/miR-20a autoregulatory feedback loop," Journal of Biological Chemistry, vol. 282, no. 4, pp. 2135-2143, 2007.

[16] M. Dews, A. Homayouni, D. Yu et al., "Augmentation of tumor angiogenesis by a Myc-activated microRNA cluster," Nature Genetics, vol. 38, no. 9, pp. 1060-1065, 2006.

[17] A. Lujambio, S. Ropero, E. Ballestar et al., "Genetic unmasking of an epigenetically silenced microRNA in human cancer cells," Cancer Research, vol. 67, no. 4, pp. 1424-1429, 2007.

[18] J. M. Thomson, M. Newman, J. S. Parker, E. M. Morin-Kensicki, T. Wright, and S. M. Hammond, "Extensive post-transcriptional regulation of microRNAs and its implications for cancer," Genes and Development, vol. 20, no. 16, pp. 2202-2207, 2006.

[19] D. Hanahan and R. A. Weinberg, "Hallmarks of cancer: the next generation," Cell, vol. 144, no. 5, pp. 646-674, 2011.

[20] C. E. Weber and P. C. Kuo, "The tumor microenvironment," Surgical Oncology, vol. 21, no. 3, pp. 172-177, 2012.

[21] J. Dou and N. Gu, "Emerging strategies for the identification and targeting of cancer stem cells," Tumor Biology, vol. 31, no. 4, pp. 243-253, 2010.

[22] M. S. Wicha, S. Liu, and G. Dontu, "Cancer stem cells: an old idea-a paradigm shift," Cancer Research, vol. 66, no. 4, pp. 1883-1890, 2006.

[23] D. Bonnet and J. E. Dick, "Human acute myeloid leukemia is organized as a hierarchy that originates from a primitive hematopoietic cell," Nature Medicine, vol. 3, no. 7, pp. 730-737, 1997.

[24] M. Al-Hajj, M. S. Wicha, A. Benito-Hernandez, S. J. Morrison, and M. F. Clarke, "Prospective identification of tumorigenic breast cancer cells," Proceedings of the National Academy of Sciences of the United States of America, vol. 100, no. 7, pp. 39833988, 2003. 
[25] S. K. Singh, C. Hawkins, I. D. Clarke et al., "Identification of human brain tumour initiating cells," Nature, vol. 432, no. 7015, pp. 396-401, 2004.

[26] S. Bao, Q. Wu, R. E. McLendon et al., "Glioma stem cells promote radioresistance by preferential activation of the DNA damage response," Nature, vol. 444, no. 7120, pp. 756-760, 2006.

[27] S. K. Singh, I. D. Clarke, T. Hide, and P. B. Dirks, "Cancer stem cells in nervous system tumors," Oncogene, vol. 23, no. 43, pp. 7267-7273, 2004.

[28] R. Galli, E. Binda, U. Orfanelli et al., "Isolation and characterization of tumorigenic, stem-like neural precursors from human glioblastoma," Cancer Research, vol. 64, no. 19, pp. 7011-7021, 2004.

[29] H. D. Hemmati, I. Nakano, J. A. Lazareff et al., "Cancerous stem cells can arise from pediatric brain tumors," Proceedings of the National Academy of Sciences of the United States of America, vol. 100, no. 25, pp. 15178-15183, 2003.

[30] A. Capela and S. Temple, "LeX/ssea-1 is expressed by adult mouse CNS stem cells, identifying them as nonependymal," Neuron, vol. 35, no. 5, pp. 865-875, 2002.

[31] T.-A. Read, M. P. Fogarty, S. L. Markant et al., "Identification of CD15 as a marker for tumor-propagating cells in a mouse model of medulloblastoma," Cancer Cell, vol. 15, no. 2, pp. 135147, 2009.

[32] M. J. Son, K. Woolard, D.-H. Nam, J. Lee, and H. A. Fine, "SSEA1 is an enrichment marker for tumor-initiating cells in human glioblastoma," Cell Stem Cell, vol. 4, no. 5, pp. 440-452, 2009.

[33] U. Karsten and S. Goletz, "What makes cancer stem cell markers different?” SpringerPlus, vol. 2, no. 1, pp. 1-8, 2013.

[34] M. Abdouh, S. Facchino, W. Chatoo, V. Balasingam, J. Ferreira, and G. Bernier, "BMI1 sustains human glioblastoma multiforme stem cell renewal," The Journal of Neuroscience, vol. 29, no. 28, pp. 8884-8896, 2009.

[35] F. Verginelli, A. Perin, R. Dali et al., "Transcription factors FOXG1 and Groucho/TLE promote glioblastoma growth," Nature Communications, vol. 4, article 2956, 2013.

[36] D. Bexell, S. Gunnarsson, P. Siesjö, J. Bengzon, and A. Darabi, "CD133+ and nestin+ tumor-initiating cells dominate in N29 and N32 experimental gliomas," International Journal of Cancer, vol. 125, no. 1, pp. 15-22, 2009.

[37] K. K. Velpula, V. R. Dasari, A. J. Tsung, D. H. Dinh, and J. S. Rao, "Cord blood stem cells revert glioma stem cell EMT by down regulating transcriptional activation of Sox 2 and Twist1," Oncotarget, vol. 2, no. 12, pp. 1028-1042, 2011.

[38] C. O. Rodini, D. E. Suzuki, N. Saba-Silva et al., "Expression analysis of stem cell-related genes reveal OCT4 as a predictor of poor clinical outcome in medulloblastoma," Journal of NeuroOncology, vol. 106, no. 1, pp. 71-79, 2012.

[39] K. Mitsui, Y. Tokuzawa, H. Itoh et al., "The homeoprotein nanog is required for maintenance of pluripotency in mouse epiblast and ES cells," Cell, vol. 113, no. 5, pp. 631-642, 2003.

[40] N. Garg, A. Po, E. Miele et al., "MicroRNA-17-92 cluster is a direct Nanog target and controls neural stem cell through Trp53inp1," The EMBO Journal, vol. 32, no. 21, pp. 2819-2832, 2013.

[41] A. Po, E. Ferretti, E. Miele et al., "Hedgehog controls neural stem cells through p53-independent regulation of Nanog," The EMBO Journal, vol. 29, no. 15, pp. 2646-2658, 2010.

[42] M. Zbinden, A. Duquet, A. Lorente-Trigos, S.-N. Ngwabyt, I. Borges, and A. Ruiz I. Altaba, "NANOG regulates glioma stem cells and is essential in vivo acting in a cross-functional network with GLI1 and p53," EMBO Journal, vol. 29, no. 15, pp. 26592674, 2010.

[43] J. Douville, R. Beaulieu, and D. Balicki, "ALDH1 as a functional marker of cancer stem and progenitor cells," Stem Cells and Development, vol. 18, no. 1, pp. 17-26, 2009.

[44] A. E. Stacy, P. J. Jansson, and D. R. Richardson, "Molecular pharmacology of ABCG2 and its role in chemoresistance," Molecular Pharmacology, vol. 84, no. 5, pp. 655-669, 2013.

[45] M. A. Varela, T. C. Roberts, and M. J. A. Wood, "Epigenetics and ncRNAs in brain function and disease: mechanisms and prospects for therapy," Neurotherapeutics, vol. 10, no. 4, pp. 621631, 2013.

[46] C. L. Gladson, R. A. Prayson, and W. M. Liu, "The pathobiology of glioma tumors," Annual Review of Pathology: Mechanisms of Disease, vol. 5, pp. 33-50, 2010.

[47] B. A. Kohler, E. Ward, B. J. McCarthy et al., "Annual report to the nation on the status of cancer, 1975-2007, featuring tumors of the brain and other nervous system," Journal of the National Cancer Institute, vol. 103, no. 9, pp. 714-736, 2011.

[48] R. Stupp, M. E. Hegi, W. P. Mason et al., "Effects of radiotherapy with concomitant and adjuvant temozolomide versus radiotherapy alone on survival in glioblastoma in a randomised phase III study: 5-year analysis of the EORTC-NCIC trial," The Lancet Oncology, vol. 10, no. 5, pp. 459-466, 2009.

[49] T. N. Ignatova, V. G. Kukekov, E. D. Laywell, O. N. Suslov, F. D. Vrionis, and D. A. Steindler, "Human cortical glial tumors contain neural stem-like cells expressing astroglial and neuronal markers in vitro," Glia, vol. 39, no. 3, pp. 193-206, 2002.

[50] G. Tabatabai and M. Weller, "Glioblastoma stem cells," Cell and Tissue Research, vol. 343, no. 3, pp. 459-465, 2011.

[51] C. Liu, J. C. Sage, M. R. Miller et al., "Mosaic analysis with double markers reveals tumor cell of origin in glioma," Cell, vol. 146, no. 2, pp. 209-221, 2011.

[52] C. Chua, N. Zaiden, K.-H. Chong et al., "Characterization of a side population of astrocytoma cells in response to temozolomide: laboratory investigation," Journal of Neurosurgery, vol. 109, no. 5, pp. 856-866, 2008.

[53] Z. Huang, L. Cheng, O. A. Guryanova, Q. Wu, and S. Bao, "Cancer stem cells in glioblastoma-molecular signaling and therapeutic targeting," Protein and Cell, vol. 1, no. 7, pp. 638655, 2010.

[54] S. A. Ciafrè, S. Galardi, A. Mangiola et al., "Extensive modulation of a set of microRNAs in primary glioblastoma," Biochemical and Biophysical Research Communications, vol. 334, no. 4, pp. 1351-1358, 2005.

[55] J. A. Chan, A. M. Krichevsky, and K. S. Kosik, "MicroRNA-21 is an antiapoptotic factor in human glioblastoma cells," Cancer Research, vol. 65, no. 14, pp. 6029-6033, 2005.

[56] L. Shi, J. Zhang, T. Pan et al., "MiR-125b is critical for the suppression of human U251 glioma stem cell proliferation," Brain Research, vol. 1312, pp. 120-126, 2010.

[57] B. Zhao, E.-B. Bian, J. Li, and J. Li, "New advances of microRNAs in glioma stem cells, with special emphasis on aberrant methylation of microRNAs," Journal of Cellular Physiology, vol. 229, no. 9, pp. 1141-1147, 2014.

[58] N. Wu, L. Xiao, X. Zhao et al., "miR-125b regulates the proliferation of glioblastoma stem cells by targeting E2F2," FEBS Letters, vol. 586, no. 21, pp. 3831-3839, 2012.

[59] J. Godlewski, M. O. Nowicki, A. Bronisz et al., "Targeting of the Bmi-1 oncogene/stem cell renewal factor by MicroRNA-128 inhibits glioma proliferation and self-renewal," Cancer Research, vol. 68, no. 22, pp. 9125-9130, 2008. 
[60] T. Papagiannakopoulos, D. Friedmann-Morvinski, P. Neveu et al., "Pro-neural miR-128 is a glioma tumor suppressor that targets mitogenic kinases," Oncogene, vol. 31, no. 15, pp. 18841895, 2012.

[61] Z.-M. Shi, J. Wang, Z. Yan et al., "MiR-128 inhibits tumor growth and angiogenesis by targeting p70S6K1," PLoS ONE, vol. 7, no. 3, Article ID e32709, 2012.

[62] Y. Zhang, T. Chao, R. Li et al., "MicroRNA-128 inhibits glioma cells proliferation by targeting transcription factor E2F3a," Journal of Molecular Medicine, vol. 87, no. 1, pp. 43-51, 2009.

[63] S. Zhao, H. Liu, Y. Liu et al., "MiR-143 inhibits glycolysis and depletes stemness of glioblastoma stem-like cells," Cancer Letters, vol. 333, no. 2, pp. 253-260, 2013.

[64] S. Zhao, Y. Deng, Y. Liu et al., "MicroRNA-153 is tumor suppressive in glioblastoma stem cells," Molecular Biology Reports, vol. 40, no. 4, pp. 2789-2798, 2013.

[65] B. Kefas, J. Godlewski, L. Comeau et al., "microRNA-7 inhibits the epidermal growth factor receptor and the akt pathway and is down-regulated in glioblastoma," Cancer Research, vol. 68, no. 10, pp. 3566-3572, 2008.

[66] L. Shi, Z. Wang, G. Sun, Y. Wan, J. Guo, and X. Fu, "MiR-145 inhibits migration and invasion of glioma stem cells by targeting ABCG2," NeuroMolecular Medicine, vol. 16, no. 2, pp. 517-528, 2014.

[67] Y. Li, F. Guessous, Z. Ying et al., "MicroRNA-34a inhibits glioblastoma growth by targeting multiple oncogenes," Cancer Research, vol. 69, no. 19, pp. 7569-7576, 2009.

[68] F. Guessous, Y. Zhang, A. Kofman et al., "microRNA-34a is tumor suppressive in brain tumors and glioma stem cells," Cell Cycle, vol. 9, no. 6, pp. 1031-1036, 2010.

[69] S. S. Rathod, S. B. Rani, M. Khan, D. Muzumdar, and A. Shiras, "Tumor suppressive miRNA-34a suppresses cell proliferation and tumor growth of glioma stem cells by targeting Akt and Wnt signaling pathways," FEBS Open Bio, vol. 4, pp. 485-495, 2014.

[70] Z. Wu, Y. Wu, Y. Tian et al., "Differential effects of miR-34c-3p and miR-34c-5p on the proliferation, apoptosis and invasion of glioma cells," Oncology Letters, vol. 6, no. 5, pp. 1447-1452, 2013.

[71] J. Mei, R. Bachoo, and C.-L. Zhang, "MicroRNA-146a inhibits glioma development by targeting Notchl," Molecular and Cellular Biology, vol. 31, no. 17, pp. 3584-3592, 2011.

[72] L. Chen, X.-R. Chen, F.-F. Chen et al., "MicroRNA-107 inhibits U87 glioma stem cells growth and invasion," Cellular and Molecular Neurobiology, vol. 33, no. 5, pp. 651-657, 2013.

[73] B. Kefas, L. Comeau, D. H. Floyd et al., "The neuronal microRNA miR-326 acts in a feedback loop with Notch and has therapeutic potential against brain tumors," Journal of Neuroscience, vol. 29, no. 48, pp. 15161-15168, 2009.

[74] R. Zhang, H. Luo, S. Wang et al., "miR-622 suppresses proliferation, invasion and migration by directly targeting activating transcription factor 2 in glioma cells," Journal of NeuroOncology, vol. 121, no. 1, pp. 63-72, 2015.

[75] J. Ma, Y. Yao, P. Wang et al., "MiR-152 functions as a tumor suppressor in glioblastoma stem cells by targeting Kruppel-like factor 4," Cancer Letters, vol. 355, no. 1, pp. 85-95, 2014.

[76] Y. Tu, X. Gao, G. Li et al., "MicroRNA-218 inhibits glioma invasion, migration, proliferation, and Cancer stem-like cell selfrenewal by targeting the polycomb group gene Bmil," Cancer Research, vol. 73, no. 19, pp. 6046-6055, 2013.

[77] J. Silber, D. A. Lim, C. Petritsch et al., "miR-124 and miR-137 inhibit proliferation of glioblastoma multiforme cells and induce differentiation of brain tumor stem cells," BMC Medicine, vol. 6, article 14, 2008.

[78] H. Xia, W. K. C. Cheung, S. S. Ng et al., "Loss of brain-enriched miR-124 microRNA enhances stem-like traits and invasiveness of glioma cells," The Journal of Biological Chemistry, vol. 287, no. 13, pp. 9962-9971, 2012.

[79] A. Bier, N. Giladi, N. Kronfeld et al., "MicroRNA-137 is downregulated in glioblastoma and inhibits the stemness of glioma stem cells by targeting RTVP-1," Oncotarget, vol. 4, no. 5, pp. 665-676, 2013.

[80] S. Tamim, D. T. Vo, P. J. Uren et al., "Genomic analyses reveal broad impact of miR-137 on genes associated with malignant transformation and neuronal differentiation in glioblastoma cells," PLoS ONE, vol. 9, no. 1, Article ID e85591, 2014.

[81] Y. Tian, Y. Nan, L. Han et al., "MicroRNA miR-451 downregulates the PI3K/AKT pathway through CAB39 in human glioma," International Journal of Oncology, vol. 40, no. 4, pp. 1105-1112, 2012.

[82] H. Gal, G. Pandi, A. A. Kanner et al., "MIR-451 and Imatinib mesylate inhibit tumor growth of Glioblastoma stem cells," Biochemical and Biophysical Research Communications, vol. 376, no. 1, pp. 86-90, 2008.

[83] B. Peng, S. Hu, Q. Jun et al., "MicroRNA-200b targets CREB1 and suppresses cell growth in human malignant glioma," Molecular and Cellular Biochemistry, vol. 379, no. 1-2, pp. 51-58, 2013.

[84] D. Men, Y. Liang, and L. Chen, "Decreased expression of microRNA-200b is an independent unfavorable prognostic factor for glioma patients," Cancer Epidemiology, vol. 38, no. 2, pp. 152-156, 2014.

[85] Q. Liu, H. Tang, X. Liu et al., "MiR-200b as a prognostic factor targets multiple members of RAB family in glioma," Medical Oncology, vol. 31, no. 3, article 859, 2014.

[86] Y. Su, Q. He, L. Deng et al., "MiR-200a impairs glioma cell growth, migration, and invasion by targeting SIM2-s," NeuroReport, vol. 25, no. 1, pp. 12-17, 2014.

[87] M.-F. Lang, S. Yang, C. Zhao et al., “Genome-wide profiling identified a set of miRNAs that are differentially expressed in glioblastoma stem cells and normal neural stem cells," PLoS ONE, vol. 7, no. 4, Article ID e36248, 2012.

[88] F. Guessous, M. Alvarado-Velez, L. Marcinkiewicz et al., "Oncogenic effects of miR-10b in glioblastoma stem cells," Journal of Neuro-Oncology, vol. 112, no. 2, pp. 153-163, 2013.

[89] L. He, J. M. Thomson, M. T. Hemann et al., "A microRNA polycistron as a potential human oncogene," Nature, vol. 435, no. 7043, pp. 828-833, 2005.

[90] D. Schraivogel, L. Weinmann, D. Beier et al., "CAMTA1 is a novel tumour suppressor regulated by $\mathrm{miR}-9 / 9^{*}$ in glioblastoma stem cells," The EMBO Journal, vol. 30, no. 20, pp. 4309-4322, 2011.

[91] A. Ernst, B. Campos, J. Meier et al., "De-repression of CTGF via the miR-17-92 cluster upon differentiation of human glioblastoma spheroid cultures," Oncogene, vol. 29, no. 23, pp. 34113422, 2010.

[92] E. Miele, F. R. Buttarelli, A. Arcella et al., "High-throughput microRNA profiling of pediatric high-grade gliomas," NeuroOncology, vol. 16, no. 2, pp. 228-240, 2014.

[93] X. H. D. Chan, S. Nama, F. Gopal et al., “Targeting glioma stem cells by functional inhibition of a prosurvival oncomiR-138 in malignant gliomas," Cell Reports, vol. 2, no. 3, pp. 591-602, 2012.

[94] D. H. Floyd, Y. Zhang, B. K. Dey et al., "Novel anti-apoptotic microRNAs 582-5p and 363 promote human glioblastoma stem 
cell survival via direct inhibition of caspase 3, caspase 9, and Bim," PLoS ONE, vol. 9, no. 5, Article ID e96239, 2014.

[95] Y. Yao, Y. Xue, J. Ma et al., "MiR-330-mediated regulation of SH3GL2 expression enhances malignant behaviors of glioblastoma stem cells by activating ERK and PI3K/AKT signaling pathways," PLoS ONE, vol. 9, no. 4, Article ID e95060, 2014.

[96] K. Katsushima, K. Shinjo, A. Natsume et al., "Contribution of microRNA-1275 to Claudin11 protein suppression via a polycomb-mediated silencing mechanism in human glioma stemlike cells," The Journal of Biological Chemistry, vol. 287, no. 33, pp. 27396-27406, 2012.

[97] D. N. Louis, H. Ohgaki, O. D. Wiestler et al., "The 2007 WHO classification of tumours of the central nervous system," Acta Neuropathologica, vol. 114, no. 2, pp. 97-109, 2007.

[98] B. S. Paugh, C. Qu, C. Jones et al., "Integrated molecular genetic profiling of pediatric high-grade gliomas reveals key differences with the adult disease," Journal of Clinical Oncology, vol. 28, no. 18, pp. 3061-3068, 2010.

[99] D. K. Birks, V. N. Barton, A. M. Donson, M. H. Handler, R. Vibhakar, and N. K. Foreman, "Survey of MicroRNA expression in pediatric brain tumors," Pediatric Blood and Cancer, vol. 56, no. 2, pp. 211-216, 2011.

[100] G. Gatta, G. Zigon, R. Capocaccia et al., "Survival of European children and young adults with cancer diagnosed 1995-2002," European Journal of Cancer, vol. 45, no. 6, pp. 992-1005, 2009.

[101] D. W. Parsons, M. Li, X. Zhang et al., "The genetic landscape of the childhood cancer medulloblastoma," Science, vol. 331, no. 6016, pp. 435-439, 2011.

[102] Y.-J. Cho, A. Tsherniak, P. Tamayo et al., "Integrative genomic analysis of medulloblastoma identifies a molecular subgroup that drives poor clinical outcome," Journal of Clinical Oncology, vol. 29, no. 11, pp. 1424-1430, 2011.

[103] D. W. Ellison, J. Dalton, M. Kocak et al., "Medulloblastoma: clinicopathological correlates of SHH, WNT, and non-SHH/WNT molecular subgroups," Acta Neuropathologica, vol. 121, no. 3, pp. 381-396, 2011.

[104] P. A. Northcott, D. J. H. Shih, M. Remke et al., "Rapid, reliable, and reproducible molecular sub-grouping of clinical medulloblastoma samples," Acta Neuropathologica, vol. 123, no. 4, pp. 615-626, 2012.

[105] S. L. Palmer, W. E. Reddick, and A. Gajjar, "Understanding the cognitive impact on children who are treated for medulloblastoma," Journal of Pediatric Psychology, vol. 32, no. 9, pp. 10401049, 2007.

[106] V. Ramaswamy, M. Remke, E. Bouffet et al., "Recurrence patterns across medulloblastoma subgroups: an integrated clinical and molecular analysis," The Lancet Oncology, vol. 14, no. 12, pp. 1200-1207, 2013.

[107] D. O. Vidal, M. M. C. Marques, L. F. Lopes, and R. M. Reis, "The role of microRNAs in medulloblastoma," Pediatric Hematology and Oncology, vol. 30, no. 5, pp. 367-378, 2013.

[108] E. Ferretti, E. De Smaele, E. Miele et al., "Concerted microRNA control of Hedgehog signalling in cerebellar neuronal progenitor and tumour cells," The EMBO Journal, vol. 27, no. 19, pp. 2616-2627, 2008.

[109] E. Ferretti, E. de Smaele, A. Po et al., "MicroRNA profiling in human medulloblastoma," International Journal of Cancer, vol. 124, no. 3, pp. 568-577, 2009.

[110] J. Pierson, B. Hostager, R. Fan, and R. Vibhakar, "Regulation of cyclin dependent kinase 6 by microRNA 124 in medulloblastoma," Journal of Neuro-Oncology, vol. 90, no. 1, pp. 1-7, 2008.
[111] K. K. W. Li, J. C. S. Pang, A. K. K. Ching et al., "miR-124 is frequently down-regulated in medulloblastoma and is a negative regulator of SLC16A1," Human Pathology, vol. 40, no. 9, pp. 1234-1243, 2009.

[112] S. Venkataraman, D. K. Birks, I. Balakrishnan et al., "MicroRNA 218 acts as a tumor suppressor by targeting multiple cancer phenotype-associated genes in medulloblastoma," Journal of Biological Chemistry, vol. 288, no. 3, pp. 1918-1928, 2013.

[113] L. Garzia, I. Andolfo, E. Cusanelli et al., "MicroRNA-199b-5p impairs cancer stem cells through negative regulation of HES1 in medulloblastoma," PLoS ONE, vol. 4, no. 3, Article ID e4998, 2009.

[114] I. Andolfo, L. Liguori, P. De Antonellis et al., "The micro-RNA 199b-5p regulatory circuit involves Hes1, CD15, and epigenetic modifications in medulloblastoma," Neuro-Oncology, vol. 14, no. 5, pp. 596-612, 2012.

[115] P. de Antonellis, C. Medaglia, E. Cusanelli et al., "MiR-34a targeting of Notch ligand delta-like 1 impairs $\mathrm{CD} 15^{+} / \mathrm{CD} 133^{+}$ tumor-propagating cells and supports neural differentiation in medulloblastoma," PLoS ONE, vol. 6, no. 9, 2011.

[116] S. D. Weeraratne, V. Amani, A. Neiss et al., "miR-34a confers chemosensitivity through modulation of MAGE-A and p53 in medulloblastoma," Neuro-Oncology, vol. 13, no. 2, pp. 165-175, 2011.

[117] T. Thor, A. Künkele, K. W. Pajtler et al., "MiR-34a deficiency accelerates medulloblastoma formation in vivo," International Journal of Cancer, vol. 136, no. 10, pp. 2293-2303, 2015.

[118] A. Gokhale, R. Kunder, A. Goel et al., "Distinctive microRNA signature of medulloblastomas associated with the WNT signaling pathway," Journal of Cancer Research and Therapeutics, vol. 6, no. 4, pp. 521-529, 2010.

[119] S. K. Singh, I. D. Clarke, M. Terasaki et al., "Identification of a cancer stem cell in human brain tumors," Cancer Research, vol. 63, no. 18, pp. 5821-5828, 2003.

[120] F. Wang, M. Remke, K. Bhat et al., "A microRNA-1280/JAG2 network comprises a novel biological target in high-risk medulloblastoma," Oncotarget, vol. 6, no. 5, pp. 2709-2724, 2015.

[121] K. Hemmesi, M. L. Squadrito, P. Mestdagh et al., "miR-135a inhibits cancer stem cell-driven medulloblastoma development by directly repressing Arhgef6 expression," Stem Cells, vol. 33, no. 5, pp. 1377-1389, 2015.

[122] T. Uziel, F. V. Karginov, S. Xie et al., “The miR-17 92 cluster collaborates with the Sonic Hedgehog pathway in medulloblastoma," Proceedings of the National Academy of Sciences of the United States of America, vol. 106, no. 8, pp. 2812-2817, 2009.

[123] P. A. Northcott, A. Fernandez-L, J. P. Hagan et al., "The miR$17 / 92$ polycistron is up-regulated in sonic hedgehog-driven medulloblastomas and induced by N-myc in sonic hedgehogtreated cerebellar neural precursors," Cancer Research, vol. 69, no. 8, pp. 3249-3255, 2009.

[124] A. H. C. Bai, T. Milde, M. Remke et al., "MicroRNA-182 promotes leptomeningeal spread of non-sonic hedgehogmedulloblastoma," Acta Neuropathologica, vol. 123, no. 4, pp. 529-538, 2012.

[125] Y.-Y. Lee, Y.-P. Yang, M.-C. Huang et al., "MicroRNA142-3p promotes tumor-initiating and radioresistant properties in malignant pediatric brain tumors," Cell Transplantation, vol. 23, no. 4-5, pp. 669-690, 2014.

[126] Z. Zhang, S. Li, and S. Y. Cheng, “The miR-183 approximately 96 approximately 182 cluster promotes tumorigenesis in a mouse model of medulloblastoma," Journal of Biomedical Research, vol. 27, no. 6, pp. 486-494, 2013. 
[127] E. Grunder, R. D’Ambrosio, G. Fiaschetti et al., "microRNA21 suppression impedes medulloblastoma cell migration," European Journal of Cancer, vol. 47, no. 16, pp. 2479-2490, 2011.

[128] Y. Lu, S. L. Ryan, D. J. Elliott et al., "Amplification and overexpression of Hsa-miR-30b, Hsa-miR-30d and KHDRBS3 at 8q24.22-q24.23 in medulloblastoma," PLoS ONE, vol. 4, no. 7, Article ID e6159, 2009.

[129] N. Karavitaki, S. Cudlip, C. B. T. Adams, and J. A. H. Wass, "Craniopharyngiomas," Endocrine Reviews, vol. 27, no. 4, pp. 371-397, 2006.

[130] E. H. Nielsen, U. Feldt-Rasmussen, L. Poulsgaard et al., "Incidence of craniopharyngioma in Denmark $(n=189)$ and estimated world incidence of craniopharyngioma in children and adults," Journal of Neuro-Oncology, vol. 104, no. 3, pp. 755763, 2011.

[131] G. R. Bunin, T. S. Surawicz, P. A. Witman, S. Preston-Martin, F. Davis, and J. M. Bruner, "The descriptive epidemiology of craniopharyngioma," Journal of Neurosurgery, vol. 89, no. 4, pp. 547-551, 1998.

[132] C. L. Andoniadou, C. Gaston-Massuet, R. Reddy et al., "Identification of novel pathways involved in the pathogenesis of human adamantinomatous craniopharyngioma," Acta Neuropathologica, vol. 124, no. 2, pp. 259-271, 2012.

[133] X. Zhu, A. S. Gleiberman, and M. G. Rosenfeld, "Molecular physiology of pituitary development: signaling and transcriptional networks," Physiological Reviews, vol. 87, no. 3, pp. 933963, 2007.

[134] M. L. Campanini, L. M. Colli, B. M. C. Paixao et al., "CTNNB1 gene mutations, pituitary transcription factors, and MicroRNA expression involvement in the pathogenesis of adamantinomatous craniopharyngiomas," Hormones and Cancer, vol. 1, no. 4, pp. 187-196, 2010.

[135] Y. Fang, X. Gu, Z. Li, J. Xiang, and Z. Chen, "miR-449b inhibits the proliferation of SW1116 colon cancer stem cells through downregulation of CCND1 and E2F3 expression," Oncology Reports, vol. 30, no. 1, pp. 399-406, 2013.

[136] J. Geng, H. Luo, Y. Pu et al., "Methylation mediated silencing of miR-23b expression and its role in glioma stem cells," Neuroscience Letters, vol. 528, no. 2, pp. 185-189, 2012.

[137] J. Finlay-Schultz, D. M. Cittelly, P. Hendricks et al., "Progesterone downregulation of miR-141 contributes to expansion of stem-like breast cancer cells through maintenance of progesterone receptor and Stat5a," Oncogene, 2014.

[138] T. S. Armstrong, E. Vera-Bolanos, and M. R. Gilbert, "Clinical course of adult patients with ependymoma: results of the Adult Ependymoma Outcomes Project," Cancer, vol. 117, no. 22, pp. 5133-5141, 2011.

[139] H. Poppleton and R. J. Gilbertson, "Stem cells of ependymoma," British Journal of Cancer, vol. 96, no. 1, pp. 6-10, 2007.

[140] M. D. Taylor, H. Poppleton, C. Fuller et al., "Radial glia cells are candidate stem cells of ependymoma," Cancer Cell, vol. 8, no. 4, pp. 323-335, 2005.

[141] U. Tabori, V. Wong, J. Ma et al., "Telomere maintenance and dysfunction predict recurrence in paediatric ependymoma," British Journal of Cancer, vol. 99, no. 7, pp. 1129-1135, 2008.

[142] T. Tihan, T. Zhou, E. Holmes, P. C. Burger, S. Ozuysal, and E. J. Rushing, "The prognostic value of histological grading of posterior fossa ependymomas in children: a Children's Oncology Group study and a review of prognostic factors," Modern Pathology, vol. 21, no. 2, pp. 165-177, 2008.
[143] F. F. Costa, J. M. Bischof, E. F. Vanin et al., "Identification of microRNAs as potential prognostic markers in ependymoma," PLoS ONE, vol. 6, no. 10, Article ID e25114, 2011.

[144] Y. Li, Y. Yuan, K. Tao et al., "Inhibition of BCR/ABL protein expression by miR-203 sensitizes for imatinib mesylate," PLoS ONE, vol. 8, no. 4, Article ID e61858, 2013.

[145] M. J. Bueno, I. P. de Castro, M. G. de Cedrón et al., "Genetic and epigenetic silencing of microRNA-203 enhances ABL1 and BCR-ABL1 oncogene expression," Cancer Cell, vol. 13, no. 6, pp. 496-506, 2008.

[146] R. Yi, M. N. Poy, M. Stoffel, and E. Fuchs, "A skin microRNA promotes differentiation by repressing 'stemness"' Nature, vol. 452, no. 7184, pp. 225-229, 2008.

[147] M. Sakurai, Y. Miki, M. Masuda et al., "LIN28: a regulator of tumor-suppressing activity of let-7 microRNA in human breast cancer," Journal of Steroid Biochemistry and Molecular Biology, vol. 131, no. 3-5, pp. 101-106, 2012.

[148] G. Tezcan, B. Tunca, A. Bekar et al., "microRNA expression pattern modulates temozolomide response in GBM tumors with cancer stem cells," Cellular and Molecular Neurobiology, vol. 34, no. 5, pp. 679-692, 2014.

[149] E. J. Devor, J. N. de Mik, S. Ramachandran, M. J. Goodheart, and K. K. Leslie, "Global dysregulation of the chromosome $14 \mathrm{q} 32$ imprinted region in uterine carcinosarcoma," Experimental and Therapeutic Medicine, vol. 3, no. 4, pp. 677-682, 2012.

[150] F. Haller, A. von Heydebreck, J. D. Zhang et al., "Localizationand mutation-dependent microRNA (miRNA) expression signatures in gastrointestinal stromal tumours (GISTs), with a cluster of co-expressed miRNAs located at 14q32.31," Journal of Pathology, vol. 220, no. 1, pp. 71-86, 2010.

[151] P. Vasanthan, V. Govindasamy, N. Gnanasegaran, W. Kunasekaran, S. Musa, and N. H. Abu Kasim, "Differential expression of basal microRNAs' patterns in human dental pulp stem cells," Journal of Cellular and Molecular Medicine, vol. 19, no. 3, pp. 566-580, 2015.

[152] R. Schneppenheim, M. C. Frühwald, S. Gesk et al., "Germline nonsense mutation and somatic inactivation of SMARCA4/ $B R G 1$ in a family with rhabdoid tumor predisposition syndrome," The American Journal of Human Genetics, vol. 86, no. 2, pp. 279-284, 2010.

[153] I. Versteege, N. Sévenet, J. Lange et al., “Truncating mutations of hSNF5/INI1 in aggressive paediatric cancer," Nature, vol. 394, no. 6689, pp. 203-206, 1998.

[154] K. Zhang, H. Gao, X. Wu et al., "Frequent overexpression of HMGA2 in human atypical teratoid/rhabdoid tumor and its correlation with let-7a3/let-7b miRNA," Clinical Cancer Research, vol. 20, no. 5, pp. 1179-1189, 2014.

[155] S. L. Yong and A. Dutta, "The tumor suppressor microRNA let-7 represses the HMGA2 oncogene," Genes and Development, vol. 21, no. 9, pp. 1025-1030, 2007.

[156] C. Mayr, M. T. Hemann, and D. P. Bartel, "Disrupting the pairing between let-7 and Hmga 2 enhances oncogenic transformation," Science, vol. 315, no. 5818, pp. 1576-1579, 2007.

[157] F. Yu, H. Yao, P. Zhu et al., "let-7 regulates self renewal and tumorigenicity of breast cancer cells," Cell, vol. 131, no. 6, pp. 1109-1123, 2007.

[158] J. Takamizawa, H. Konishi, K. Yanagisawa et al., "Reduced expression of the let-7 microRNAs in human lung cancers in association with shortened postoperative survival," Cancer Research, vol. 64, no. 11, pp. 3753-3756, 2004. 
[159] A. Malek, E. Bakhidze, A. Noske et al., "HMGA2 gene is a promising target for ovarian cancer silencing therapy," International Journal of Cancer, vol. 123, no. 2, pp. 348-356, 2008.

[160] A. T. Yachnis, D. Neubauer, and D. Muir, "Characterization of a primary central nervous system atypical teratoid/rhabdoid tumor and derivative cell line: immunophenotype and neoplastic properties," Journal of Neuropathology and Experimental Neurology, vol. 57, no. 10, pp. 961-971, 1998.

[161] J. A. Biegel, "Molecular genetics of atypical teratoid/rhabdoid tumor," Neurosurgical Focus, vol. 20, no. 4, p. E11, 2006.

[162] D. M. Parham, D. A. Weeks, and J. B. Beckwith, “The clinicopathologic spectrum of putative extrarenal rhabdoid tumors: an analysis of 42 cases studied with immunohistochemistry or electron microscopy," American Journal of Surgical Pathology, vol. 18, no. 10, pp. 1010-1029, 1994.

[163] S.-H. Chiou, C.-L. Kao, Y.-W. Chen et al., "Identification of CD133-positive radioresistant cells in atypical teratoid/rhabdoid tumor," PLoS ONE, vol. 3, no. 5, Article ID e2090, 2008.

[164] C.-L. Kao, P.-I. Huang, P.-H. Tsai et al., "Resveratrol-induced apoptosis and increased radiosensitivity in CD133-positive cells derived from atypical teratoid/rhabdoid tumor," International Journal of Radiation Oncology Biology Physics, vol. 74, no. 1, pp. 219-228, 2009.

[165] H.-I. Ma, C.-L. Kao, Y.-Y. Lee et al., "Differential expression profiling between atypical teratoid/rhabdoid and medulloblastoma tumor in vitro and in vivo using microarray analysis," Child's Nervous System, vol. 26, no. 3, pp. 293-303, 2010.

[166] S. L. Asa and S. Ezzat, "The pathogenesis of pituitary tumours," Nature Reviews Cancer, vol. 2, no. 11, pp. 836-849, 2002.

[167] S. Ezzat and S. L. Asa, "Mechanisms of disease: the pathogenesis of pituitary tumors," Nature Clinical Practice Endocrinology and Metabolism, vol. 2, no. 4, pp. 220-230, 2006.

[168] T. Palumbo, F. R. Faucz, M. Azevedo, P. Xekouki, D. Iliopoulos, and C. A. Stratakis, "Functional screen analysis reveals miR$26 \mathrm{~b}$ and miR-128 as central regulators of pituitary somatomammotrophic tumor growth through activation of the PTEN-AKT pathway," Oncogene, vol. 32, no. 13, pp. 1651-1659, 2013.

[169] H. Butz, I. Likó, S. Czirják et al., "Down-regulation of Wee1 kinase by a specific subset of microRNA in human sporadic pituitary adenomas," Journal of Clinical Endocrinology and Metabolism, vol. 95, no. 10, pp. E181-E191, 2010.

[170] C. H. McGowan and P. Russell, "Human Weel kinase inhibits cell division by phosphorylating p34cdc2 exclusively on Tyr15," The EMBO Journal, vol. 12, no. 1, pp. 75-85, 1993.

[171] B. N. Davis-Dusenbery and A. Hata, "Mechanisms of control of microRNA biogenesis," Journal of Biochemistry, vol. 148, no. 4, pp. 381-392, 2010.

[172] A. Kotani, D. Ha, D. Schotte, M. L. Den Boer, S. A. Armstrong, and H. F. Lodish, "A novel mutation in the miR-128b gene reduces miRNA processing and leads to glucocorticoid resistance of MLL-AF4 acute lymphocytic leukemia cells," Cell Cycle, vol. 9, no. 6, pp. 1037-1042, 2010.

[173] A. Maitra, I. I. Wistuba, C. Washington et al., "High-resolution chromosome $3 p$ allelotyping of breast carcinomas and precursor lesions demonstrates frequent loss of heterozygosity and a discontinuous pattern of allele loss," American Journal of Pathology, vol. 159, no. 1, pp. 119-130, 2001.

[174] M. Li, W. Fu, L. Wo, X. Shu, F. Liu, and C. Li, "MiR-128 and its target genes in tumorigenesis and metastasis," Experimental Cell Research, vol. 319, no. 20, pp. 3059-3064, 2013.
[175] S. Mi, J. Lu, M. Sun et al., "MicroRNA expression signatures accurately discriminate acute lymphoblastic leukemia from acute myeloid leukemia," Proceedings of the National Academy of Sciences of the United States of America, vol. 104, no. 50, pp. 19971-19976, 2007.

[176] A. Bottoni, M. C. Zatelli, M. Ferrcin et al., "Identification of differentially expressed microRNAs by microarray: a possible role for microRNA genes in pituitary adenomas," Journal of Cellular Physiology, vol. 210, no. 2, pp. 370-377, 2007.

[177] A. H. Stegh, O. Schickling, A. Ehret et al., "DEDD, a novel death effector domain-containing protein, targeted to the nucleolus," The EMBO Journal, vol. 17, no. 20, pp. 5974-5986, 1998.

[178] Z. Mao, D. He, J. Zhou et al., "Differential expression of microRNAs in GH-secreting pituitary adenomas," Diagnostic Pathology, vol. 5, no. 1, article 79, 2010.

[179] F. Salehi, K. Kovacs, B. W. Scheithauer, R. V. Lloyd, and M. Cusimano, "Pituitary tumor-transforming gene in endocrine and other neoplasms: a review and update," Endocrine-Related Cancer, vol. 15, no. 3, pp. 721-743, 2008.

[180] F. Zhi, Q. Wang, D. Deng et al., "MiR-181b-5p downregulates NOVA1 to suppress proliferation, migration and invasion and promote apoptosis in astrocytoma," PLoS ONE, vol. 9, no. 10, Article ID e109124, 2014.

[181] W. M. Pardridge, "shRNA and siRNA delivery to the brain," Advanced Drug Delivery Reviews, vol. 59, no. 2-3, pp. 141-152, 2007.

[182] M. E. Hayes, D. C. Drummond, D. B. Kirpotin et al., "Genospheres: self-assembling nucleic acid-lipid nanoparticles suitable for targeted gene delivery," Gene Therapy, vol. 13, no. 7, pp. 646-651, 2006.

[183] R. Saito, M. T. Krauze, C. O. Noble et al., "Convectionenhanced delivery of Ls-TPT enables an effective, continuous, low-dose chemotherapy against malignant glioma xenograft model," Neuro-Oncology, vol. 8, no. 3, pp. 205-214, 2006.

[184] G. Chen, W. Zhu, D. Shi et al., "MicroRNA-181a sensitizes human malignant glioma U87MG cells to radiation by targeting Bcl-2," Oncology Reports, vol. 23, no. 4, pp. 997-1003, 2010.

[185] L. Wang, Z. Shi, C. Jiang et al., "MiR-143 acts as a tumor suppressor by targeting N-RAS and enhances temozolomideinduced apoptosis in glioma," Oncotarget, vol. 5, no. 14, pp. 5416-5427, 2014.

[186] J. Xu, X. Liao, and C. Wong, "Downregulations of B-cell lymphoma 2 and myeloid cell leukemia sequence 1 by microRNA 153 induce apoptosis in a glioblastoma cell line DBTRG-05MG," International Journal of Cancer, vol. 126, no. 4, pp. 1029-1035, 2010.

[187] C.-Z. Zhang, J.-X. Zhang, A.-L. Zhang et al., "MiR-221 and miR-222 target PUMA to induce cell survival in glioblastoma," Molecular Cancer, vol. 9, article 229, 2010.

[188] C. Shang, Y. Guo, Y. Hong, Y. Liu, and Y. Xue, "MiR-21 upregulation mediates glioblastoma cancer stem cells apoptosis and proliferation by targeting FASLG," Molecular Biology Reports, vol. 42, no. 3, pp. 721-727, 2015.

[189] B. X. Lei, Z. H. Liu, Z. J. Li, C. Li, and Y. F. Deng, "miR-21 induces cell proliferation and suppresses the chemosensitivity in glioblastoma cells via downregulation of FOXO1," International Journal of Clinical and Experimental Medicine, vol. 7, no. 8, pp. 2060-2066, 2014.

[190] C. H. Yang, J. Yue, S. R. Pfeffer et al., "MicroRNA-21 promotes glioblastoma tumorigenesis by down-regulating insulin-like growth factor-binding protein-3 (IGFBP3)," The Journal of Biological Chemistry, vol. 289, no. 36, pp. 25079-25087, 2014. 
[191] C. H. Yang, S. R. Pfeffer, M. Sims et al., "The oncogenic microRNA-21 inhibits the tumor suppressive activity of FBXO11 to promote tumorigenesis," The Journal of Biological Chemistry, vol. 290, no. 10, pp. 6037-6046, 2015.

[192] I. S. Pateras, K. Apostolopoulou, K. Niforou, A. Kotsinas, and V. G. Gorgoulis, "p57KIP2: 'kip'ing the cell under control," Molecular Cancer Research, vol. 7, no. 12, pp. 1902-1919, 2009.

[193] F. C. Amaral, N. Torres, F. Saggioro et al., "MicroRNAs differentially expressed in ACTH-secreting pituitary tumors," Journal of Clinical Endocrinology and Metabolism, vol. 94, no. 1, pp. 320323, 2009.

[194] A. Catania, F. Maira, E. Skarmoutsou, F. D’Amico, R. Abounader, and M. C. Mazzarino, "Insight into the role of microRNAs in brain tumors (review)," International Journal of Oncology, vol. 40, no. 3, pp. 605-624, 2012.

[195] E. Gentilin, F. Tagliati, C. Filieri et al., "MiR-26a plays an important role in cell cycle regulation in ACTH-secreting pituitary adenomas by modulating protein kinase Cdelta," Endocrinology, vol. 154, no. 5, pp. 1690-1700, 2013. 

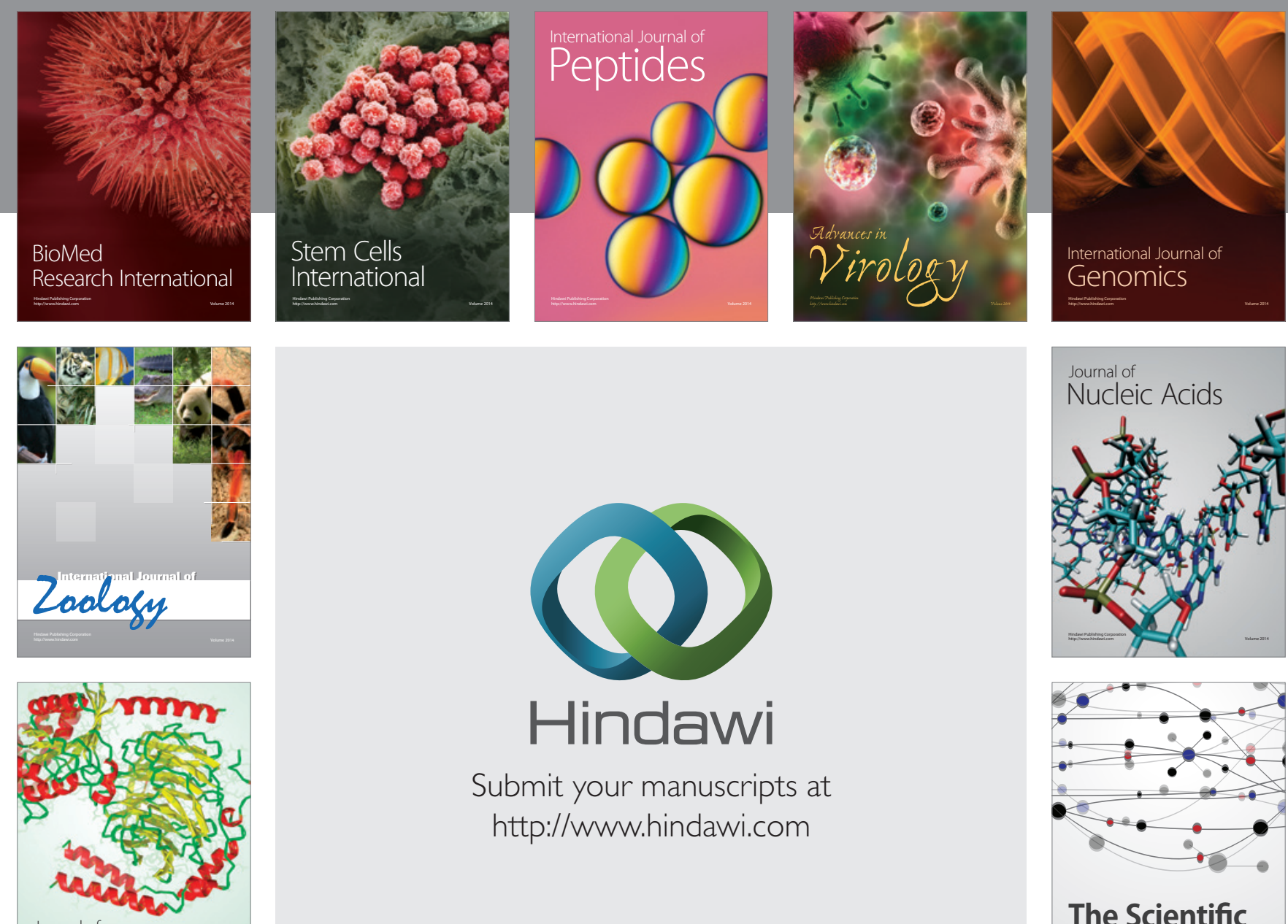

Submit your manuscripts at

http://www.hindawi.com

Journal of
Signal Transduction
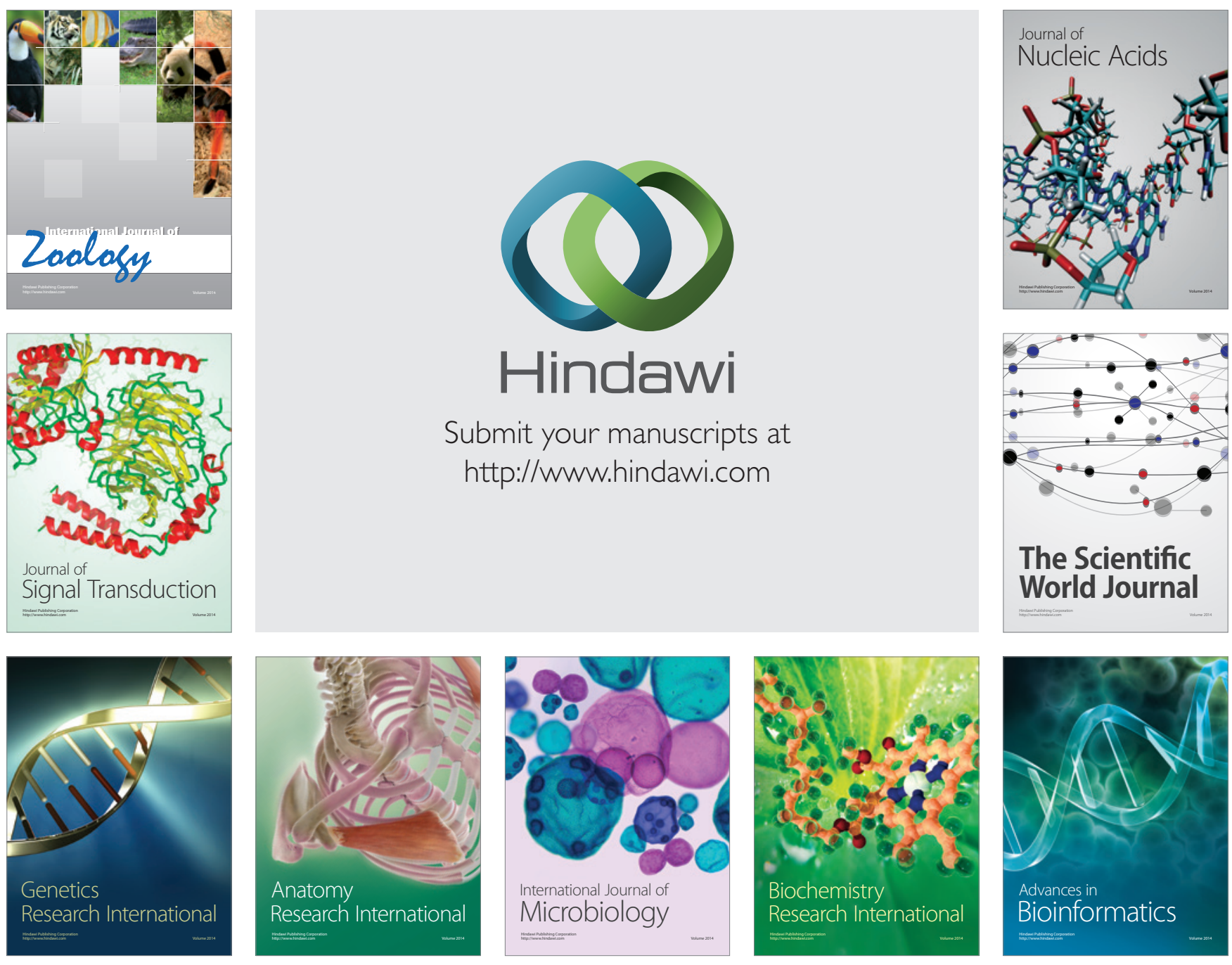

The Scientific World Journal
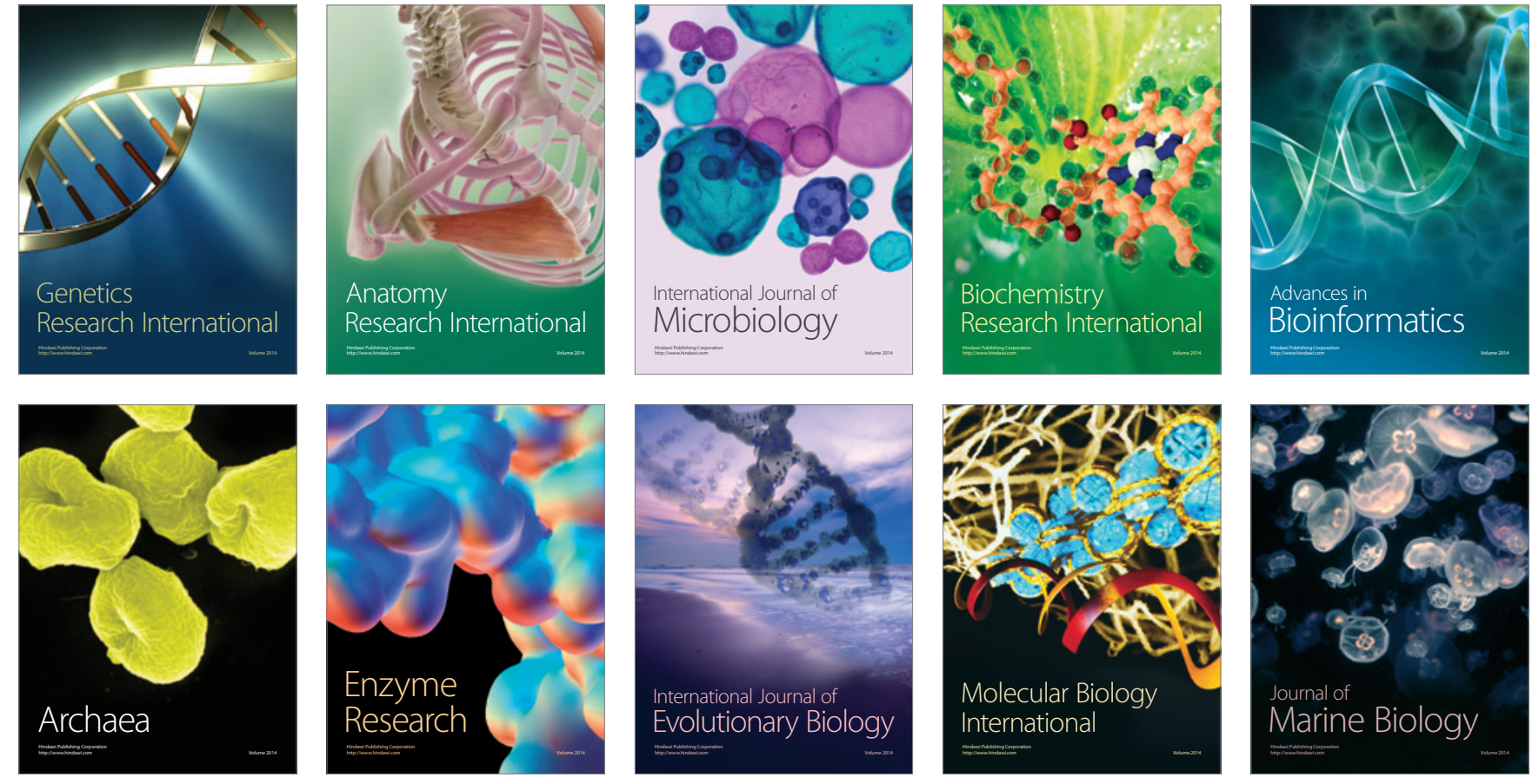